\title{
OSTRACISMO POLÍTICO Y AFRANCESAMIENTO. JOSÉ DE MAZARREDO, UN MARINO ILUSTRADO MINISTRO DE JOSÉ I
}

\author{
Íñigo Bernaola Martín \\ Universidad Nacional de Educación a Distancia \\ inigobernaola@gmail.com
}

RESUMEN: José de Mazarredo será uno de los marinos protagonista del desarrollo de la marina de guerra ilustrada de la segunda mitad del siglo XVIII, instrumento al servicio de la gestión del imperio colonial y su defensa territorial y comercial. La irrupción del arrollador impulso de una nación en armas como la francesa conducirá a España a una política exterior supeditada a los intereses de Napoleón, y una marina secuestrada en su propio beneficio. Su resistencia a esa política, así como la denuncia constante de las carencias de la Armada, le harán sufrir el ostracismo y destierro a manos del todopoderoso Manuel Godoy. Los intereses personales del ministro y dinásticos de una monarquía en decadencia difícilmente hacen tolerable la presencia de quienes, como nuestro personaje, reclaman una modernización y adecuación a la realidad de los instrumentos del estado moderno. Su regreso a la vida pública con el cambio dinástico, como ministro del nuevo rey francés, y su actuación política, serán el objeto de análisis de este trabajo.

Palabras clave: Guerra, siglo XVIII, Ilustración, Revolución, marina española, afrancesados, España, Francia, Carlos IV, Napoleón Bonaparte, José Bonaparte, Guerra de la Independencia, José de Mazarredo.

\section{POLITICAL OSTRACISM AND FRENCHIFICATION. JOSEPH DE MAZARREDO, AN ENLIGHTENED NAVY OFFICER MINISTER OF JOSEPH I}

ABSTRACT: José de Mazarredo will be one of the naval officers protagonists of the development of the Spanish Navy in the Age of Enlightenment in the second half of the XVIII century, as a perfect tool for managing colonial empire and its commercial and territorial defense. The overwhelming impulse of a nation in 
arms as France will lead Spain to a foreign policy subordinated to the interests of Napoleon, and a Spanish Navy abducted from his own benefit. His resistance to this policy and the constant denunciation of the deficiencies of the Spanish Navy made him suffer the subsequent banishment and ostracism at the hands of the most powerful politician Manuel Godoy. The personal interests of the minister and dynastic of a monarchy in decay hardly make tolerable the presence of those who, like our protagonist, calling for a modernization and adaptation to the reality of the instruments of the modern state. His return to public life with the dynastic change, as minister of the new French king, and his action will be the subject analysis of this work.

Keywords: War, eighteenth century, Enlightenment, Revolution, Spanish Navy, Spain, France, Carlos IV, Napoleon Bonaparte, Joseph Bonaparte, the Peninsular War, José de Mazarredo.

Recibido: 16 de Diciembre de 2015

Aceptado: 3 de Marzo de 2016

El teniente general José de Mazarredo y Salazar fue un marino ilustrado que contribuyó al desarrollo científico, organizativo y militar de la Marina borbónica, y que como diplomático y político acabó siendo protagonista de la caída del Antiguo Régimen, de un cambio dinástico y de la Guerra de la Independencia española. La irrupción de la Revolución Francesa, la llegada de Napoleón al poder y sus efectos en España le situarán en primera línea de los acontecimientos políticos y militares del momento como embajador de la España del reformismo borbónico en la Francia republicana del primer cónsul Napoleón. El interés estratégico de Napoleón por la flota española provocará la designación de un marino para tal misión en 1799.

La alianza entre dos países de sistemas políticos tan antagónicos, como son el Antiguo Régimen y la Revolución, hacen que la experiencia diplomática vivida por este personaje histórico tenga un notable interés. Máxime cuando nos referimos a un periodo histórico, que si bien en los últimos años -como veremos más adelante- ha sido objeto de investigaciones y publicaciones que han Ilenado una anterior laguna historiográfica, carecía de un tratamiento específico hasta hace escasos años. Del mismo modo, si bien la Guerra de la Independencia y la España constitucionalista de 1812 siempre despertaron un temprano interés por parte de los historiadores, la España josefina y su administración no ha sido hasta fechas más cercanas a nosotros objeto específico de interés, relegado siempre a un papel secundario.

En el caso concreto de nuestro personaje aún más escasas son, no ya las publicaciones, sino las referencias a los años que llenaron el último periodo de 
su vida. Su retiro en Bilbao entre 1801 y 1804, su destierro en 1804, y su regreso a la vida pública como ministro de Marina de José Bonaparte entre 1808 y 1812, puesto en el que murió. Será protagonista directo, a su pesar, de la Guerra de la Independencia.

En lo referido a las fuentes documentales contamos con la suerte de disponer de la práctica totalidad de correspondencia y documentación generadas durante la misión diplomática de Mazarredo en París en el periodo comprendido entre 1799 y 1801 en el Archivo del Museo Naval y el Archivo Histórico Nacional, y de disponer de abundante documentación referida a su posterior caída en desgracia y regreso a la vida pública con José Bonaparte en 1808.

Al periodo de actividad diplomática que desencadenó su marginación de la vida pública, a su retiro en Bilbao, y a su regreso a la vida política de la mano de José I se dedicara el presente artículo. Será precisamente su exceso de celo profesional el que termine por conducirle al ostracismo. Su denuncia constante de las carencias de un régimen incapaz de dotar de manera moderna y adecuada una marina de guerra. Siendo este segundo aspecto de nuestro interés también, por su propio contenido y como posible explicación a su adscripción al nuevo régimen de Bayona, a José Bonaparte como rey de España, en la esperanza de un país regenerado ante una realidad de hechos consumados.

A Mazarredo su condición de afrancesado le valió la crítica del resto de marinos y cierto ostracismo del que fue definitivamente rehabilitado en 1847 al darse su nombre a un buque de guerra. Sus aportaciones científicas y militares, pero sobre todo organizativas, le valieron un pronto interés por parte de algunos marinos historiadores en la segunda mitad del siglo XIX ${ }^{1}$ y mitad del siglo $X^{2}$.

Agustín Guimerá Ravina, investigador del CSIC especializado en el estudio de la historia naval y marítima en el atlántico en el siglo XVIII, en su extensa producción bibliográfica se refiere ampliamente a Mazarredo, habiendo publicado varios artículos específicamente dedicados a su figura ${ }^{3}$ y a la guerra naval

1. Fueron otros dos marinos, don Francisco de Paula Pavía y don Cesáreo Fernández Duro, quienes se dedicaron al estudio de su labor. Precisamente se conservan varias cartas manuscri tas de Mazarredo en el fondo documental que lleva el nombre de este último en el Archivo del Museo Naval. PAVÍA, F.: Galería biográfica de los generales de marina, jefes y personajes notables que figuraron en la misma corporación desde 1700 a 1868. Madrid, 1873 (Tomo II). FER NÁNDEZ DURO, C.: Disquisiciones náuticas. Madrid, 1879, vol. IV, pp. 157182.

2. Enrique Barbudo Duarte publica en 1945 su obra José de Mazarredo. Teniente General de la Armada siendo el primero que se dedica al estudio de su figura de manera monográfica. BARBUDO DUARTE, E.: Don José de Mazarredo, teniente general de la Real Armada. Madrid. 1945. Aunque se refiere escasamente como ministro de marina de José I.

3. GUIMERÁ RAVINA, A.: "Mazarredo, un marino ilustrado y científico" en VV.AA.: José de Mazarredo y Salazar. XXXIX Jornadas de Historia Marítima en Madrid (octubre 2009). Madrid. Instituto de Historia y Cultura Naval, 2010, pp. 27 41. GUIMERÁ RAVINA, A.: "Métodos de liderazgo naval en una época revolucionaria: Mazarredo y Jervis (1779-1808)" en GARCÍA 
durante la Revolución y el Imperio. También contamos con bibliografía específica referida a la marina durante la Guerra de la Independencia como la monografía de Carlos Martínez Valverde ${ }^{4}$, o las XXXVI y XXXVIII Jornadas del Instituto de Historia y Cultura $\mathrm{Naval}^{5}$ y el recientemente publicado trabajo de Vicente Ruiz García ${ }^{6}$, entre otros ${ }^{7}$. Algunos de ellos ampliamente referenciados en los siguientes capítulos del presente trabajo.

Al margen de las dedicadas a nuestro personaje, son numerosas las publicaciones de carácter general sobre el reinado de Carlos IV, la Guerra de la Independencia y la España de José I en las que aparece recogida y analizada su participación en los acontecimientos políticos y militares ocurridos en el periodo. Desde la Historia de Carlos IV escrita por su contemporáneo Andrés Muriel ${ }^{8}$ (1776-1840), quien dedicó parte de su producción historiográfica a la defensa y justificación de los afrancesados, hasta las publicaciones más cercanas en el tiempo sobre ese mismo periodo de autores como Seco Serrano ${ }^{9}$ y Emilio de La

HURTADO, M.R., GONZÁLEZ LOPO, D.L., MARTíNEZ RODRÍGUEZ, E. (eds.): El mar en los siglos modernos. Santiago de Compostela. Xunta de Galicia, 2009, vol. II. GUIMERÁ RAVINA, A.: "Napoleón y la Armada" en VV.AA.: Poder terrestre y poder naval en la época de la batalla de Trafalgar. XXXI Congreso Internacional de Historia Militar en Madrid (2005). Madrid. Minis terio de Defensa, Secretaría General Técnica, 2006, pp. 519 538. GUIMERÁ RAVINA, A. y GARCÍA FERNÁNDEZ, N.: "Un consenso estratégico: las Ordenanzas Navales de 1793" en Anuario de Estudios Atlánticos. Las Palmas de Gran Canaria. Casa de Colón, Cabildo de Gran Canaria, 2008. Vol. 54 II, pp. 4381.

4. MARTíNEZ VALVERDE, C.: La Marina en la Guerra de la Independencia. Madrid. Editora Nacional, 1974.

5. VV.AA.: La Marina en la Guerra de la Independencia II y III. XXXVI y XXXVIII Jornadas de Historia Marítima en Madrid (abril 2008 y marzo 2009). Madrid. Instituto de Historia y Cultura Naval, 2010.

6. RUIZ GARCíA, V.: Las naves de las Cortes (1808-1812). El último servicio de la marina de la llustración. Madrid. Sílex, 2013.

7. BLANCO NÚÑEZ, J. M.: "La Armada en la Guerra de la Independencia", en La Guerra de la Independencia (1808-1814). El pueblo español, su ejército y sus aliados frente a la ocupación napoleónica. Madrid. Ministerio de defensa, Secretaría General Técnica, 2007, pp. 81 105; FERNÁNDEZ DURO, C., Armada española desde la unión de los reinos de Castilla y de Aragón. [Edición facsímil de 1900]. Madrid. Museo Naval, 1972, tomos VIII y IX; GUIMERÁ RAVINA, A.: "Bloqueo imperfecto, guerra anfibia y liderazgo: Cádiz, 1810" en GARCÍA HUR TADO, M.R. (coord.): La Armada española en el siglo XVIII. Ciencia, hombres y barcos. Madrid. Sílex Ediciones, 2012, pp. 207 232; HALL, C. D., Welington's Navy. Sea Power and the Peninsular War, 1807-1814. London. Chatham Publishing, 2004; RODRíGUEZ GONZÁLEZ, A.: "Cádiz en la estrategia naval de la guerra de la Independencia, 1808 1814", en A. GUIMERÁ RAVINA y BLANCO NÚÑ̃EZ, J. M. (Coords.): Guerra naval en la Revolución y el Imperio: bloqueos y operaciones anfibias, 1793-1815. Madrid. Marcial Pons, 2008, pp. 321340.

8. MURIEL, A.: Historia de Carlos IV. Madrid. Real Academia de la Historia, 1984.

9. SECO SERRANO, C.: "La política exterior de Carlos IV" en BATLLORI, M. (Coord.): La época de la llustración. Las Indias y la política exterior. Madrid. Espasa Calpe, 1987 ( $\mathrm{H}^{\mathrm{a}}$ de Espa ña de Ramón Menéndez Pidal. Tomo XXXI, vol. II), pp. 448732. 
Parra $^{10}$. Y las dedicadas a la Guerra de la Independencia y al reinado de José I de los profesores Miguel Artola ${ }^{11}$, Manuel Moreno Alonso ${ }^{12}$, Juan López Tabar ${ }^{13}$, entre otros muchos, y que nos sirven para conocer la participación del personaje en el periodo.

Las investigaciones y publicaciones del profesor La Parra han Ilenado una anterior laguna historiográfica sobre las relaciones entre la España de Carlos IV y la Revolución que, como se lamentaba hace algunos años el profesor Javier Fernández Sebastián en la Revista de historia contemporánea (1993), carecía de un tratamiento específico ${ }^{14}$.

Actualmente en la Universidad de la Rioja, Aleix Romero Peña ha publicado numerosos artículos dedicados a la biografía de Mariano Luís de Urquijo ${ }^{15}$. Su tarea desarrollada al frente de la Secretaría de Estado (1798-1800) coincidirá prácticamente en el tiempo con la misión diplomática de José de Mazarredo ante Napoleón. Igualmente compartirá con su paisano y amigo en su ciudad natal de Bilbao su retiro, apartados por Godoy, y posterior destierro como con-

10. LA PARRA LÓPEZ, E.: Manuel Godoy. La aventura del poder. Barcelona. Tusquets, 2002. Esta publicación de uno de los principales especialistas en la figura de Godoy, que contribuye a la desmitificación del personaje, nos interesa para ampliar el conocimiento del poder omní modo que ejerció de 1792 a 1808, y como afectó a la carrera militar de Mazarredo y su misión diplomática.

11. Aunque arranca en 1808, es un gran estudio sobre el paso de una experiencia del régimen monárquico absolutista a la monarquía josefina, e incluye extensas referencias José de Mazarredo, su biografía y su perfil militar y política hasta ocupar el ministerio de la Mari na. Véase ARTOLA GALLEGO, M.: Los Afrancesados [1953]. Madrid. Alianza editorial, 2008.

12. MORENO ALONSO, M.: Napoleón. La aventura de España. Madrid. Sílex, 2004. Escla rece numerosas claves para entender este momento de la historia de España en el que se enmar ca el presente trabajo, así como a sus personajes. Coinciden personajes como Mazarredo, Napoleón, Wellington, Soult, Massena, Villeneuve, José Bonaparte, Nelson, Castaños, Goya, Churruca, Gravina, Álava, Carlos IV y Godoy. Un sin fin de personas que se vieron abocadas a defender ideales, planteamientos de vida y nuevas formas de hacer la guerra.

13. LÓPEZ TABAR, J. 2011: Los famosos traidores. Los afrancesados durante la crisis del Antiguo Régimen (1808-1833). Madrid. Editorial Nueva, 2001. Este historiador especializado en el estudio de los afrancesados, además de la referida monografía cuanta con una abundante producción bibliográfica en artículos.

14. Javier Fernández Sebastián en la Revista de Historia Contemporánea, no 9 (1992), pp. 319 325, editada por el Departamento de Historia Contemporánea de la UPV a propósito de la monografía de LA PARRA LÓPEZ, E.: La alianza de Godoy con los Revolucionarios (España y Francia a fines del siglo XVIII). Madrid. CSIC, 1992.

15. ROMERO PEÑA, A.: La política exterior del ministro Urquijo. España y las embajadas de París, Viena y Lisboa durante la Guerra de la Segunda Coalición, 1798-1800. (Trabajo de sufi ciencia s.p.) Universidad de La Rioja. También ROMERO PEÑA, A.: "Mariano Luís de Urquijo. Biografía de un ilustrado", en Sancho el sabio: Revista de Cultura e investigación vasca, 34, (2011), Vitoria Gasteiz, pp. 5578. 
secuencia de los acontecimientos de la Zamacolada ${ }^{16}$, así como la participación en las Cortes de Bayona y regreso a la vida pública formando parte ambos del gobierno de José Bonaparte ${ }^{17}$.

\section{Mazarredo, un marino ilustrado}

José de Mazarredo culminará una brillante carrera alcanzando el mando de la Armada del Océano ${ }^{18}$ en 1797, no sin dudas del rey ${ }^{19}$. Reticencias provocadas precisamente por sus constantes denuncias y puesta en evidencia de las carencias de la flota a lo largo de su vida profesional. Y quizás por haber manifestado en algún modo su oposición al gobierno de Godoy ${ }^{20}$. Será en calidad de Coman-

16. ROMERO PEÑA, A.: "Mariano Luís de Urquijo, testigo y protagonista involuntario del motín de la Zamacolada" en Cuadernos de investigación histórica, 33 (2009), pp. 115148.

17. Además de los artículos recogidos, su reciente tesis doctoral titulada Mariano Luis de Urquijo (1769-1817). Biografía política en claroscuro de un personaje y una época amplia nota blemente el conocimiento referido a este periodo. Nos ayuda a conocer mejor las relaciones diplomáticas y militares de la España de Carlos IV con la Francia de la Revolución y el Imperio, el ostracismo sufrido en los últimos años del reinado de Carlos IV y su participación en el gobierno de José I. ROMERO PEÑA, A.: Mariano Luís de Urquijo (1769-1817). Biografía política en claroscuro de un personaje y una época. Tesis doctoral dirigida por Carlos Navajas Zubeldía y Bernardo Muniesa Brito. Logroño. Universidad de La Rioja, 2013.

18. A.H.N., Estado. Leg., 4939, correspondencia a Manuel Godoy. Isla de León, 1797, 11 de abril. Comunicando que ha mandado arbolar el navío Concepción y poner en él su insignia de mando.

19. BARBUDO DUARTE, E.: Don José de Mazarredo..., op. cit., pp. 71 72. El rey que ini cialmente designo al Teniente General Don Francisco de Borja como sustituto de Luís de Cór dova, pero "varios ilustres jefes de la Armada... decidieron hacer saber al Rey como el estado físico del General Borja no le hacía ser el más apropiado para reorganizar y poner a punto una Escuadra en derrota; en cambio el Teniente General Mazarredo..., contando solamente cin cuenta y dos años de edad, era,... la persona indicada para rehacer aquella Armada, levantar su moral y llevarla a la victoria". Siendo nombrado el 11 de marzo de 1797.

20. La correspondencia con Godoy es muy clarificadora respecto de la sinceridad con que el marino traslada sus opiniones. La denuncia constante, sin ambigüedades, fueron causa sufi ciente para incomodar a un Godoy acosado permanentemente por las críticas de cada vez más amplios sectores y relevarle en sus funciones. Fueron más de uno los intentos de derrocar del gobierno a Godoy, articulados en diversas conspiraciones. Nos interesa mencionar en este pun to una de ellas por su relación con nuestro personaje, la Conspiración de San Blas. Organizada por un grupo de "gentes de letras" ilustradas, fue descubierta el 3 de febrero de 1795. Durante el proceso no hubo referencia alguna al nombre de Mazarredo ni de otros notables, por parte de los encausados, pero sí con posterioridad. El principal encausado en la conspiración, Juan Bautista Picornell, fue condenado a prisión y trasladado a Venezuela, al Castillo de La Guaira donde acabaría participando en la conspiración criolla de Gual y España de 1797. Sería en el proceso abierto en la Audiencia de Caracas donde, interesados en buscar la complacencia de Madrid extendiendo su investigación a la de San Blas de 1795, recogerían testimonio indirecto de la participación en aquella de Mazarredo, así como de otros oficiales del ejército y miem bros de la nobleza y el Consejo de Estado. Se trataba de personajes cuyo testimonio era indi 
dante General de la Armada del Océano cuando el militar también asuma su misión diplomática a partir del 29 de agosto de 1799 en un nuevo contexto de alianza con la República francesa acordada en el Tratado de Basilea de 1795.

Mazarredo en calidad de embajador extraordinario y ministro plenipotenciario $^{21}$ tendrá la total confianza de Madrid, donde Godoy ha sido sustituido por su amigo y paisano Mariano Luís de Urquijo en la Secretaría de Estado. Además, ya había demostrado, desde que asumió el mando de la escuadra del Océano en tiempos de Godoy, el celo con el que priorizaba la protección de los navíos españoles evitando cualquier enfrentamiento arriesgado con la flota británica ${ }^{22}$. Y de nuevo lo hará en la primavera de 1799 en que, a pesar de denunciar las carencias ${ }^{23}$, por insistencia francesa se unieron ambas flotas en Cádiz y después se dirigieron a Brest con grave riesgo de exponerse al peligro de un enfrentamiento con la inglesa.

Mazarredo dará muestras de representar la firme actitud de independencia que Urquijo, respaldado por el rey, de momento, pretende reclamar huyendo de cualquier subordinación a Francia. Mazarredo evitará sucesivamente cualquier propuesta que venga del primer cónsul Napoleón y ponga el riesgo la integridad de su escuadra, consciente de las carencias, contando con el total apoyo del rey en su actuación ${ }^{24}$. Evitará en repetidas ocasiones que parta la flota española junto con la francesa persiguiendo objetivos maximalistas como eran la invasión de Inglaterra o Irlanda, que provocarían un enfrentamiento abierto y directo con la inglesa, abocado al seguro fracaso. Mazarredo realizará a Napoleón propuestas alternativas más razonables, con planes más concretos encami-

recto porque procedía de la información que habían escuchado de Picornell, a quien habían conocido en La Guaira. En AGUIRREZABAL, M. J. y COMELLAS, J. L.: "La conspiración de Picornell (1795) en el contexto de la prerrevolución liberal española" en Revista de Historia Contemporánea (1). Sevilla. Universidad de Sevilla, 1982 pp. 7 38. El profesor La Parra consi dera que se trataba de una simple relación de personalidades en las que probablemente los conspiradores confiaban idealmente para dirigir la monarquía en sustitución de Godoy sin ni siquiera haber contado con ellos. Si hubiera sido de otra forma, Godoy hubiese actuado contra todos ellos. En LA PARRA LÓPEZ, E.: Manuel Godoy. La aventura del poder. Barcelona. Tus quets, 2002, p. 133.

21. PAVÍA, F.: Galería biográfica de los generales de marina..., op. cit., Tomo II, p. 439.

22. ROMERO PEÑA, A.: "Mariano Luís de Urquijo...", op. cit., p. 60.

23. A.H.N. Estado. Leg. 4939, correspondencia de Mazarredo con Urquijo. Cádiz, 1799, 12 de abril. En la que denunciará "en tal día como hoy en el mes antecedente representé a Vd. la calamidad de esta marina, á que me contestó con fecha del 20 y volví a representarle el 29 acre cida como era natural, no habiéndose recibido en el intermedio más de medio millón de reales, imagine $\mathrm{Vd}$. qual deberá ser ahora sin ningún ingreso posterior...".

24. A.M.N., Colección "Antonio de Mazarredo". Leg. 2391. Madrid, 1800, 27 de enero, Mariano Luís de Urquijo en carta particular comunica a Mazarredo el aprecio del Rey a toda su actuación, folio 18. 
nados a la recuperación de Menorca y el socorro de Malta, y sobretodo insistirá en la conveniencia de trasladar la flota combinada a Cádiz por hallarse reforzada la flota inglesa del canal ${ }^{25}$.

Pero, los intentos de Urquijo y Mazarredo por devolverla a Cádiz, se verán siempre frustrados por la intercesión directa de Bonaparte con Carlos IV. Al regreso de las campañas de Italia en julio de 1800, Bonaparte se aprovechará de la receptividad con que la familia real española se muestra dispuesta a compensar el engrandecimiento de Parma. La actitud de Urquijo tratando de llevarse de Brest a Cádiz la flota española, entre otros asuntos, complicaba las relaciones del gobierno español y francés. Ésta actitud y las inclinaciones regalistas de Urquijo $^{26}$, precipitarían su caída. De la caída de Urquijo, a pesar auto exculparse en sus memorias ${ }^{27}$, Godoy fue el principal beneficiario. Cevallos sustituiría a Urquijo al frente de la Secretaría de Estado, pero la política exterior de España será directamente asumida por Godoy, quien recupera todo el ascendente sobre los reyes desde su posición de consejero, sin entrar a formar parte del gobierno ${ }^{28}$.

El 25 de diciembre Mazarredo felicitaba a Cevallos ${ }^{29}$, y éste responde el 2 de enero con el consentimiento del Rey para que la flota española permanezca en Bres $^{30}$. La poca disposición de Mazarredo de supeditar los intereses de España a los de Napoleón, entran ahora en contradicción con las ambiciones dinásticas de su monarca. El 18 de febrero, recibía comunicación de su cese al mando de la escuadra del Océano ${ }^{31}$ y su sustitución por Gravina de acuerdo con los deseos del propio Bonaparte, siendo este marino del agrado de Godoy. Mazarredo pasará a ocupar el puesto de comandante general del departamento de Cádiz ${ }^{32}$

25. Léase a este respecto el interesante análisis el artículo de GUIMERÁ RAVINA, A.: "Napoleón y la Armada" en VV.AA.: Poder terrestre..., op. cit., pp. 519538.

26. ROMERO PEÑA, A.: "Mariano Luís de Urquijo...", op. cit., pp. 6365.

27. GODOY Y ÁlVAREZ DE FARIA, M.: Memorias, ed. de LA PARRA, E. y LARRIBA, E. Ali cante. Universidad de Alicante, 2008, pp. 731 744. En el Tomo III, capítulo IV, Godoy recuerda los hechos y causas que provocaron la caída de Urquijo tratando de justificarse y evitar cual quier responsabilidad, aunque signifique su propia promoción.

28. LA PARRA LÓPEZ, E.: Manuel Godoy..., op. cit., p. 292.

29. A.M.N., Colección "Antonio de Mazarredo". Leg. 2391, carta de Mazarredo a Don Pedro de Cevallos. París, 1800, 25 de diciembre, folios 219 220. Por la que da la enhorabuena por su nombramiento como primer secretario de Estado. Aprovecha para poner de manifiesto las necesidades económicas en las que se encuentra la escuadra.

30. A.M.N., Colección "Antonio de Mazarredo". Leg. 2392, carta de Don Pedro Cevallos a Mazarredo. 1801, 2 de enero, folio, 1. Por la que se comunica a Mazarredo el consentimiento del Rey para que la escuadra permanezca en Brest, en vista de la negociación de paz con Inglaterra.

31. BARBUDO DUARTE, E.: Don José de Mazarredo..., op. cit., pp. 114.

32. A.M.N., Colección "Antonio de Mazarredo". Leg. 2354, 1801, 7 de marzo. Oficios sobre el regreso de Don José de Mazarredo desde Brest para hacerse cargo del mando del Departamento de Cádiz, folio 93. 
solicitando en septiembre de 1801 su cese y retirarse a Bilbao "para que me pueda trasladar a Vizcaya mi patria" ${ }^{\prime 3}$, y no sin antes haber remitido al rey un informe sobre su misión diplomática en París ${ }^{34}$. Hará una propuesta de regeneración, que sin respuesta le llevará a su retiro a Bilbao. Allí se encontrará con Urquijo quien había pasado del destierro a prisión en Pamplona, consiguiendo la gracia real de la libertad en octubre de 1802 a cambio de continuar su confinamiento en Bilbao ${ }^{35}$.

\section{La Zamacolada}

Establecido en Bilbao y ocupado en atender sus intereses particulares y familiares, después de cuarenta años como marino difícilmente podía desvincularse de los negocios de la Armada. Mantendrá correspondencia con sus compañeros, y su nombre volverá a aparecer en el informe favorable a la creación de un Almirantazgo emitido por quien fuera el ministro de Marina don Antonio Valdés. Aparecerá propuesto para dirigir el nuevo proyecto de Almirantazgo, siendo esta la opinión unánime de la Marina española ${ }^{36}$. El proyecto fue puesto en marcha, pero no fue llamado.

33. A.M.N, Colección "Antonio de Mazarredo". Leg. 2353, 1801, 11 de septiembre. Oficios entre Don José de Mazarredo y Don Antonio Caballero sobre su relevo en la Capitanía General del Departamento de Cádiz y su destierro en las Provincias Vascongadas, folio 194.

34. Es interesante destacar alguno de sus comentarios por resultar premonitorios en ciertos aspectos. En el informe insistirá en que "mis esfuerzos en mis muchas propuestas siempre fija ron en que la combinación era inútil" y en que "la escuadra española se hubiese desvanecido poco menos que como el humo al viento... la voluntad y el genio de Bonaparte y su ignorancia en materias de Marina, en lo que es un navío y una escuadra, en lo que constituye su conser vación o dura y en lo que puede y no puede con relación a los medios del enemigo, hubieran producido aquel triste resultado". Añadirá que "le incomodaba a Bonaparte el no poder con migo y que nunca me comunicaría sus planes exponiéndolos a mi examen... y así no he extra ñado lo que naturalmente habrá sucedido de que insinuase a V.M. no ser yo necesario allí... y que la combinación del cuerpo principal de ellas esté al mando de un general francés". Asu miendo "la superioridad del enemigo" traslada al rey su sincera opinión respecto de ambas marinas española y francesa "siendo la mayor fortuna el que se conserven cual ahora, para separarse a la cesión de aquella", y haciendo una previsión de que "a los diez años de paz ten drá Francia una fuerza respetable de mar". Una vez realizado el análisis de su misión en París, hará una denuncia de "la decadencia del cuerpo de oficiales de la armada" y del personal en general, e insistirá en que "esta regeneración de hombres de mar es la primer obra grande nece saria para la marina". A.M.N., Colección "Antonio de Mazarredo". Leg. 2392, 1801, 10 de mayo, folios 7883.

35. ROMERO PEÑA, A.: "Mariano Luís de Urquijo...", op. cit., p. 67. Donde dice que fue "recibido al inicio de su destierro en Bilbao con fiestas de homenaje, agradeciéndole su papel de benefactor" según queda recogido en URQUIJO Y MUGA, M. L.: Apuntes para la memoria sobre mi vida política, persecuciones y trabajos padecidos en ella, ed. de ROMERO PEÑA, A. Logroño. Siníndice, 2010, p. 90.

36. BARBUDO DUARTE, E.: Don José de Mazarredo..., op. cit., p. 122. 
Transcurría su vida en retiro en Bilbao, cuando surgió un incidente en la villa ${ }^{37}$ que acabaría afectándole a pesar de no haber participado hasta ese momento de la vida política local, ya enrarecida por las tensas relaciones entre la pujante villa de Bilbao y las anteiglesias del entorno, como Begoña y Abando. El 17 de noviembre de 1803 se ratificaba la Real Orden del 31 de diciembre de 1801 por la que daba permiso para la construcción de un puerto en Abando. El crecimiento económico y poblacional de Bilbao, posibilitado por sus privilegios entre otros factores, condicionaba el desarrollo de los territorios vecinos que tratarán de encontrar mecanismos como el nuevo puerto de la Paz que les permitiese también su crecimiento y prosperidad, buscando el amparo de Godoy ${ }^{38}$. La respuesta de la villa de Bilbao nombrando a Godoy alcalde honorífico de la villa, en cuyo nombre tomará Urquijo posesión del cargo, no servirá para evitar que prosiga adelante el proyecto del puerto.

Concedido el permiso real, se traslada a las Juntas Generales de Guernica de finales de julio de 1804 la cuestión para su ratificación. Simón Bernardo de

37. Conocido como la Zamacolada, será éste un hecho crucial en la historia contemporá nea vizcaína, siendo por ello abundante la bibliografía existente. Pero nos interesan sobre todo para la reconstrucción de los acontecimientos los testimonios de algunos de sus protagonistas, como el de su amigo Urquijo, con quien vivió de manera paralela los acontecimientos y sus consecuencias. En ROMERO PEÑA, A.: "Mariano Luís de Urquijo, testigo y protagonista invo luntario del motín de la Zamacolada" en Cuadernos de investigación histórica, 33 (2009), pp. 115 148. Y el testimonio del propio José de Mazarredo acerca de los acontecimientos recogido en MAZARREDO, J.: Representación de D. Joseph de Mazarredo al señor Rey D. Carlos IV sobre su ostracismo de Bilbao [Santoña, 8 de diciembre de 1804]. Madrid. Imprenta de Ibarra, 1810. Será precisamente en su primer destino de destierro después de la injusta condena que le rela ciona con los hechos, en Santoña, donde redactará y firmará con fecha de 8 de diciembre de 1808 su manifiesto dirigido a Carlos IV exculpándose de cualquier responsabilidad en los acon tecimientos ocurridos. Reivindicará su trayectoria profesional en respuesta al injusto trato que siente está recibiendo. En el A.M.N., se conserva copia manuscrita original de su representa ción. A.M.N., Colección "Antonio de Mazarredo". Tomo VII. Representación de Don José de Mazarredo a Carlos IV sobre su ostracismo de Bilbao. 1804. Leg. 2337, folios, 84 89. Se con serva también en el AHN el proceso contra Mariano Luís de Urquijo, entre los que destacan entre otros documentos (cartas a Godoy...) el interrogatorio al que fue sometido. A.H.N., Con sejos, Leg. 51535. Contiene: Pieza de Reales Órdenes pertenecientes a la comisión sobre los alborotos ocurridos en Vizcaya, 1805, 16 de febrero de 1805, y representación particular del Exmo. Sr. D. Mariano Luís de Urquijo a Godoy, de 12 de febrero 1805. Se conserva también en A.M.N. Colección "Antonio de Mazarredo". Tomo XXIV. Oficios de Don José de Mazarredo des de Santoña y el Príncipe de la Paz desde San Lorenzo del Escorial sobre los acontecimientos ocurridos en Vizcaya, el juicio al que ha sido sometido y las sucesivas residencias que debe fijar según las circunstancias. 1804 1807. Leg. 2354, folios 136160.

38. A.H.N., Consejos. Leg., 51535. 1804, 28 de diciembre, carta firmada por el Príncipe de la Paz acompañada de expediente formado a instancia del Señorío de Vizcaya "sobre que el Alcalde de la Villa de Bilbao no exerza jurisdicción alguna en la anteiglesia de Abando, con forme a los establecido en la Escritura de transación y concordia que expresa". 
Zamácola, perteneciente a la nobleza rural, defenderá los intereses de las anteiglesias consiguiendo para Abando la aprobación del puerto. El éxito de Zamácola sobre la villa y el consulado de Bilbao parece definitivo. Sin embargo, es tratado en las mismas Juntas, muy oportunamente para los intereses de Bilbao, el debate para llegar a un acuerdo de un alistamiento militar general ordenado por el rey. Aprobado también, la población vizcaína, que tenía por honor la dispensa militar, recibirá la noticia con una protesta y levantamientos generalizados culpando a Zamácola de lo ocurrido. Relata el propio Mazarredo, en su Representación dirigida a Carlos IV, como tiene conocimiento de los acontecimientos sintiendo la necesidad de tratar de detener todo aquello, siendo frenado por su propia salud y familia para que no intervenga. Nos describe como las anteiglesias de Abando y Begoña solicitaron que se presentara el corregidor, representación de la corona en Vizcaya, para presidir ambos Ayuntamientos y presentar el mencionado decreto de alistamiento de Guernica ante la población. También reclaman el acceso a la armería del Señorío. Aceptadas ambas, en ese contexto de amotinamiento algunos centenares de hombres armados entran en Bilbao, irrumpen en la Diputación y apresan al corregidor y diputados generales. Son trasladados a la casa consistorial de Abando y encerrados en un calabozo $^{39}$. Designado el licenciado José Javier Goitia por los amotinados como su representante debido a su carácter de letrado, obtendrá que revoquen los acuerdos de las últimas Juntas, anulando el decreto de alistamiento, y que convoquen una nueva. A pesar de ello, los amotinados no liberan a los prisioneros y ante la perspectiva de que se desencadenase un fatal desenlace para los apresados, Goitia acudirá en auxilio de Mazarredo pidiendo su ayuda por ser reconocida y respetada persona, además de militar de la máxima graduación. Acompañado de su amigo Urquijo de quien recabará su apoyo por tener "tan superior locución" a la suya propia, accederá a intermediar y dirigirse a Abando. En un entorno de máxima tensión, de enorme tumulto, en el que la multitud trató de linchar y acabar con la vida de los dos diputados y el corregidor aún después de haber llegado a un acuerdo, Mazarredo y Urquijo interceden para evitarlo y ofrecen sus propias casas para su custodia. Pasaron los días en sus casas "en continua lucha con armados", y "estuvieron sus vidas tan expuestas como las de los mismos a quienes" salvaron ${ }^{40}$. Durante su proceso en el interrogatorio, Urquijo se referirá a Mazarredo a quién "no podré jamás alabar bastante el trabajo y tesón... ni decir los empellones y golpes que llevamos..." ${ }^{41}$.

39. ROMERO PEÑA, A.: "Mariano Luís de Urquijo, testigo y protagonista...", op. cit., pp. 118123

40. MAZARREDO, J.: Representación de D. Joseph de Mazarredo al señor Rey D. Carlos IV..., op. cit., pp. 1419.

41. A.H.N., Consejos. Leg., 51535. 1805, 12 de febrero, representación de Mariano Luís de Urquijo a Godoy, folios 2450. 
Las noticias llegan a la corte, donde es malinterpretada la participación de Mazarredo y Urquijo al entenderse que tenían la responsabilidad de lo ocurrido, siendo emitida orden de detención y destierro contra ambos. Godoy quien ya había demostrado su animadversión hacía el personaje por la denuncia y crítica hacia el gobierno, vio en el motín de Vizcaya un intento del defenestrado Mazarredo por desposeerle del gobierno ${ }^{42}$. Incapaces las autoridades locales de sofocar el levantamiento, será necesario el traslado de tropas para su represión. Como comandante en jefe, al frente estará el Brigadier Don Benito de San Juan. Será a quien se le encomiende también la tarea de detener a Mazarredo y Urquijo para su traslado custodiados a Burgos y después Santoña y ponerlos a disposición de la justicia. La detención de quienes no habían cometido falta alguna se realizó de madrugada y sin tiempo ni siquiera para ponerse "ropa de abrigo alguna ni sombrero" como relata él mismo. Fue en la casa de su amigo Urquijo donde fue detenido de manera sorprendente la medianoche del día 23 de septiembre, habiéndose desplazado con engaño hasta allí por orden del brigadier San Juan pensando que se trataba de una "cierta diligencia"43. Aunque durante el proceso no pudo descubrirse ningún hecho criminal en su actuación, se le trasladó la voluntad del rey de que fijase su residencia a una distancia superior a las veinte leguas de Madrid, Sitios Reales y Señorío de Vizcaya. En esos términos se dirige el brigadier San Juan a Mazarredo desde Bilbao a Santoña en una carta fechada el 1 de junio de $1805^{44}$.

Llevado a Santoña primero, y Pamplona más adelante, pudo regresar a Bilbao después de tres años de destierro, "es de suponer que hasta principios de 1808 [...] pues hasta entonces no abandonaron Bilbao las tropas del Brigadier San Juan, en cuya ocasión se levantaron todos los castigos" ${ }^{\prime 45}$.

Sin duda la forma en que Carlos IV y su gobierno trataron a su persona, el pago injusto y arbitrario a todos sus años de meritorio servicio, la manera en que fue sometido al ostracismo y persecución a pesar de sus cualidades y respeto profesado por compañeros, acabarían por conducirle a una posición de

42. O'DONELL, H.: La campaña de Trafalgar. Tres naciones en pugna por el dominio del mar (1805). Madrid. La esfera de los libros, 2005, p. 54.

43. MAZARREDO, J.: Representación de D. Joseph de Mazarredo al señor Rey D. Carlos IV..., op. cit., p. 21.

44. "Aunque la conducta observada en el tiempo de las ocurrencias por el Señor Don José Domingo de Mazarredo no se han descubierto ser criminales de los S.M. se da por servido es su soberana voluntad que fije su residencia fuera del Señorío a distancia de veinte leguas y tam bién lo verificará de Madrid y Sitios Reales." A.M.N. Colección "Antonio de Mazarredo". Leg. 2354. Bilbao, 1805, 1 de marzo. Carta del brigadier San Juan a Mazarredo, quien está en San toña. Bilbao, folio 143.

45. NúÑ̃EZ IGLESIAS, I.: El teniente general de la Real Armada Don José de Mazarredo Salazar y Gortázar. Madrid. Diputación de Vizcaya, 1945, p. 100. 
disgusto frente a quienes gobernaban. "Situación que iba a influir [...] en su posterior actitud política" 46 a juicio de Barbudo Duarte. En su Representación al rey defendiendo su gestión durante aquellos acontecimientos y tratando de clarificar los motivos que le condujeron a participar, es interesante destacar la forma sincera en que se permite dirigirse al monarca, como ya lo hiciera en cuestiones estrictamente relacionadas con la Marina. Se atreve a decirle como hubiese actuado su padre, Carlos III77.

La anteposición de sus convicciones frente a cualquier consideración política, y la firmeza y sinceridad con que defendía estas le llevó a tener frecuentes choques con sus superiores políticos, como ocurrió en numerosas ocasiones con Godoy, que no marinos ${ }^{48}$. Las razones para procesarle no están claras y parece que respondieron a la suspicacia del favorito ${ }^{49}$.

Al margen de que desde una lectura local significase una brecha importante en la tensión entre foralismo y centralismo ${ }^{50}$, lo cierto es que este acontecimiento acabó teniendo repercusiones en el ámbito internacional. El necesario recurso al ejército obligó a Godoy a ordenar el traslado de tropas a Bilbao desde El Ferrol. Para ello se ordenó la rehabilitación de seis buques de guerra desarmados situados en aquel puerto, donde se encontraban además sometidos al bloqueo por parte inglesa una fuerza naval de cinco navíos franceses y uno holandés, pertenecientes a la escuadra del contralmirante Gourdon. Aprovechando la salida de los buques españoles con destino a Bilbao, inmediatamente mostrarán los franceses su intención de utilizar la operación española para partir esquivando el bloqueo. Ello provocará la reacción inglesa y a punto estuvo de provocar un conflicto con España. Godoy desistirá de sus planes renuncian-

46. BARBUDO DUARTE, E.: Don José de Mazarredo..., op. cit., p. 126.

47. "Si fue tal nuestro tesón y prudencia en aquel día, no se acreditó menos en los dos siguientes... ni cesó de acreditarse todo el espacio sucesivo hasta la llegada de las tropas de V.M., para que la disposición de su destino en caso de verificarse no se mirase por los Aldeanos sino como toda paternal, dirigida únicamente a su bien y a la buena administración de justicia. Con el tesón y prudencia debimos usar y usamos del amor y de la dulzura en lo que exigía con descendencia. La dureza en el modo y la negación absoluta solo podían ser armas de los que no han estudiado a los hombres agitados en masa. El sabio Carlos Tercero, de tan digna y vene rada memoria, dio la lección de cómo debe tratárseles, aun aclamando como aclamaban a S.M.: y el no guardarla en nuestro caso hubiera sido soplar las mechas, y abrasarse el suelo des de luego que prendiese la menor chispa". A.M.N., Colección "Antonio de Mazarredo". Leg. 2337. Santoña, 1804, 8 de diciembre, representación de Don José de Mazarredo a Carlos IV sobre su ostracismo de Bilbao, folio 88.

48. DEZCALLAR DE MAZARREDO, R.: "El Almirante Mazarredo, ilustrado y afrancesado". Revista internacional de los estudios vascos, RIEV Cuadernos, 4 (2009), San Sebastián, p. 229.

49. O'DONELL, H.: La campaña de Trafalgar. Tres naciones en pugna por el dominio del mar (1805). Madrid. La esfera de los libros, 2005, p. 54.

50. ROMERO PEÑA, A.: "Mariano Luís de Urquijo, testigo y protagonista...", op. cit., p. 45. 
do al rearme de los barcos españoles y su regreso al arsenal. Las tropas serían enviadas por tierra para sofocar el motín vizcaíno ${ }^{51}$.

\section{La batalla de Trafalgar y la ausencia de Mazarredo}

La paz de Amiens firmada en 1802 pronto demostró que no sería duradera, a pesar de que Godoy trató de mantener a España al margen del conflicto sin éxito presionado por el recientemente nombrado cónsul vitalicio Napoleón Bonaparte. Quedará evidenciado en la firma de un acuerdo comercial con Francia, el permiso de acceso a sus buques en los puertos españoles y la obligación contraída para el pago de un subsidio de 6.000.000 millones de reales mensuales a Napoleón, recogido todo ello en el Tratado de subsidio. Unas obligaciones demasiado elevadas como para que Inglaterra le restase importancia.

Como hemos visto, la España de Godoy intentó mantenerse al margen, utilizado incluso el Tratado de subsidio como medio para obtener tiempo y comprar la neutralidad sin renunciar a contactos con Inglaterra ${ }^{52}$, a quien tratará de no provocar -como vimos a propósito del envío de tropas por mar- para solucionar un asunto interno, un motín en Bilbao. Pero, estando aún en paz con Inglaterra, no tardará ésta en realizar agresiones, e incluso apoderarse de la flota que regresaba de la América española con una elevada cantidad en metálico, declarándose la guerra ${ }^{53}$.

Napoleón recién proclamado Emperador, hará de la invasión y conquista de Inglaterra su primordial objetivo político, Ilegando a reunir hasta 150.000 soldados en Boulogne con la intención desembarcar en Inglaterra. Para tener éxito una operación como esta requería distraer la flota británica que protegía el Canal. Con tal finalidad el almirante Villeneuve elaborará un complejo plan de distracción con la flota combinada española, al frente de la cual estaría Gravina. Napoleón se mostraba muy contento con la designación de este marino que había sustituido a Mazarredo en la embajada ante Francia y al mando de la escuadra en Brest, felicitándole muy sinceramente por ello, a diferencia de José de Mazarredo, de quien no guardaba buen recuerdo por sus constantes objeciones ${ }^{54}$.

51. O'DONELL, H.: La campaña de Trafalgar..., op. cit., pp. 5455.

52. LA PARRA, E.: Manuel Godoy..., op. cit., pp. 320321.

53. El 5 de octubre de 1804 cuatro fragatas procedentes de Montevideo fueron apresadas con cuatro millones de pesos y un importante volumen de mercancías coloniales provocando un fuerte rechazo popular que proporcionó a Godoy la excusa para declarar la guerra contra Inglaterra. LA PARRA, E.: Manuel Godoy..., op. cit., p. 322. Véase el catálogo de la exposición organizada en torno a este acontecimiento en el Museo Arqueológico Nacional y el Museo Naval en el año 2014. VV.AA.: El último viaje de la Fragata Mercedes. La razón frente al expolio. Un tesoro cultural recuperado. Madrid. Ministerio de Cultura, 2014.

54. O'DONELL, H.: La campaña de Trafalgar..., op. cit., p. 67. 
El mando supremo de la flota española debiera haber recaído por antigüedad, aptitud y méritos a Mazarredo, pero eran muchos los elementos que jugaban en su contra. Sobre todo, su actitud crítica hacia la política del gobierno de España y el mal recuerdo que guardaban los franceses del tiempo de su embajada en París. En la correspondencia de Napoleón con Tayllerand se comparaba favorablemente a Gravina frente a Mazarredo, a "quien consideraba un verdadero animal (bête) $)^{\prime 55}$. Sus denuncias constantes referidas al estado de precariedad de la flota, la demanda constante a Godoy de modernización de la flota y su carácter independiente le habían alejado de la corte hacía tiempo, y su injusto destierro en Santoña y Pamplona a propósito de la Zamacolada, no dejaron ninguna opción a su candidatura. La marginación de Mazarredo, quien representaba para muchos compañeros la gran esperanza del resurgimiento de la Armada, constituyó un escándalo en su época. Otra hubiera sido la historia, según algunos expertos, si se hubiese designado para el mando a este experimentado marino que contaba entonces con 60 años y ya había dado muestras de su alta capacitación en un contexto similar de flota combinada, el de la Guerra de la Independencia de Estados Unidos. Desde su posición de mayor general salvó hasta en cuatro ocasiones a las escuadras hispano-francesas de la derrota a manos de las inglesas en las operaciones del Canal de la Mancha ${ }^{56}$, Ilegándoles a infringir serios reveses como el de las Azores ya descrito anteriormente.

Ahora llevarían a cabo un complejo plan de operaciones con todo aquello que Mazarredo había rechazado siempre: mantener la flota combinada unida, ponerla bajo mando francés y enfrentarla sin el debido aprovisionamiento y adiestramiento de la flota en operaciones bélicas a la marina inglesa.

Tras el encuentro en el cabo de Trafalgar frente a Cádiz el 21 de octubre de 1805, la escuadra franco española sufrió una gran derrota a manos Nelson. El acierto en la táctica y pericia en el mando del almirante inglés, un revolucionario de la guerra en el mar, frente a la mediocridad del almirante francés Villeneuve, que actuó en ocasiones en contra de las indicaciones de los mandos españoles, hicieron posible la victoria de aquellos a pesar de la superioridad numérica y de la capacidad de fuego de la Escuadra Combinada. Treinta y tres navíos hispano-franceses frente a veintisiete ingleses. Pero, al margen de cualquier mérito personal, son dos factores estructurales los que hacían previsible un desenlace como este, y que ya habían sido puestos de manifiesto por el teniente general Mazarredo. Tales como fueron el deficitario sistema de alista-

55. O'DONELL, H.: Idem, pp. 179182.

56. GUIMERÁ RAVINA, A.: "Godoy y la Armada", en MELÓN, M. A., LA PARRA, E., TOMÁS PÉREZ, F. (eds.): Manuel Godoy y su tiempo. Congreso internacional Manuel Godoy (1767-1851) en Badajoz (octubre 2001). Mérida. Editora Regional de Extremadura, 2003, vol. I, pp. 394395. 
miento de las tripulaciones, la carencia de su adiestramiento y formación ${ }^{57}$, la escasez y deficiencia del suministro en los pertrechos y avituallamientos para la dotación de la flota. Fueron precisamente estas denuncias constantes, y las tareas encaminadas a su enmienda las que caracterizaron el mando de Mazarredo. Y su determinación de resistirse repetidamente al requerimiento de Napoleón y del almirante Bruix de poner a su disposición la flota española, las que precipitaron su caída. Quizás de haber continuado Mazarredo al mando de la escuadra española en la combinada, el desastre de Trafalgar no se hubiese producido ${ }^{58}$. Él no se hubiese dejado arrastrar por la improvisación impulsiva hacia semejante catástrofe y hubiera "esperado una oportunidad favorable para infringir daños a la Royal Navy en un combate bien planteado"59. José Ignacio González-Aller dirá de Mazarredo que era "el profesional más completo de todos los de su tiempo, pero era incómodo al mando por decir siempre la verdad sobre el estado de la Armada, y debido a ello no tuvo ocasión de estar al mando de la Escuadra del Océano en las grandes funciones de San Vicente y Trafalgar. Con él embarcado en el navío insignia español, otra hubiese sido la historia ${ }^{60 \prime \prime}$. Su independencia, y su resistencia a cualquier aventura ya había quedado demostrada en ocasiones anteriores por encima de las consecuencias que pudiera tener en su propia carrera. Su clara conciencia de las limitaciones, e inferioridad, en las que se encontraba la Armada así le habían conducido a actuar. La sustitución por Gravina al frente de la Escuadra del Océano y en la embajada en Francia ${ }^{61}$ había perseguido precisamente evitar cualquier gesto de independencia respecto del mando francés. Al menos, quedaba el consuelo de que en la presente campaña se habían comprometido un número de navíos

57. "El 19 de octubre de 1805, contra todo pronóstico y lógica, el almirante Villeneuve dio orden de zarpar a la Combinada. Los mandos españoles, como Gravina, Escaño o Álava, esta ban totalmente en contra, al igual que muchos oficiales franceses como Magon, Camas o Denieport. Pero un mandato directo en la Armada era irrefutable y nadie osó amotinarse contra él, especialmente en el caso del almirante Gravina, si bien todos sabían que era una locura". En CAYUELA FERNÁNDEZ, J.: "Nelson y el bloqueo de Cádiz", op. cit., pp. 244249.

58. "Buena prueba de la clara visión naval de Mazarredo fue que cuando no se atendieron sus indicaciones y consejos, sobrevinieron grandes desastres: Cabo de San Vicente y Trafal gar...". En BARBUDO DUARTE, E.: Don José de Mazarredo..., op. cit., p. 6.

59. GUIMERÁ A.: "Británicos y franceses ante el combate de Trafalgar" en VV.AA.: De la Paz de País a Trafalgar (1763-1805). El acontecer bélico y sus protagonistas. X Jornadas de Historia Militar en Madrid (noviembre 2001). Madrid. Centro Superior de Estudios de la Defensa Nacio nal, 2005, p. 122.

60. GONZÁLEZ ALLER, J. I.: "Algunas consideraciones estratégicas y tácticas sobre la cam paña de Trafalgar" en BUTRÓN, G., GUIMERÁ, A. y RAMOS, A. (Coords.): Trafalgar y el mundo atlántico. Madrid. Marcial Pons, 2004, pp. 184185.

61. "Pero un mandato directo en la Armada era irrefutable y nadie osó amotinarse contra él Villeneuve especialmente en el caso del almirante Gravina". En CAYUELA FERNÁNDEZ, J.: "Nelson y el bloqueo de Cádiz...", op. cit., p. 244. 
menor de los posibles al llegar al convencimiento de que las tripulaciones disponibles aconsejaban no armar la totalidad de buques disponibles. En cierto modo, se había tenido en cuenta el informe que a tal propósito emitiera el almirante Mazarredo un tiempo atrás, provocando su postergación, poniendo de manifiesto la incapacidad del país para abastecer correctamente todos los barcos. Se había considerado al menos en el sentido de adecuar el número de barcos armados del total de los existentes al de tripulaciones, aunque no hasta sus últimos extremos ${ }^{62}$.

Gran Bretaña había conjurado la tremenda amenaza que representaba una invasión ${ }^{63}$. Bonaparte abandonó sus planes contra Inglaterra y dedicó su atención a sus enemigos continentales. España había perdido en una jornada 10 navíos, con un coste de mil muertos -entre ellos excelentes oficiales como Churruca, Alcalá Galiano o Alcedo y Bustamante-, y aún más heridos. Algunos de los cuales, como Gravina, morirían posteriormente como consecuencia de ello. A la quiebra del Ejército que significó la guerra de los Pirineos, se sumará este el desastre naval de Trafalgar que, si bien no fue el final de la Armada, si marcó un punto de inflexión en el largo proceso de decadencia comenzado en 1795. Es precisamente en esta situación de indefensión en la que sorprenderán más adelante al país los acontecimientos de 1808. La ocupación francesa y las abdicaciones de Carlos IV y Fernando VII en favor de Napoleón.

\section{Su participación en la Constitución de Bayona y comienzo del reinado de José I}

Napoleón en su proclama del 25 de mayo de 1808 manifestó a pesar de las abdicaciones en él de los dos monarcas anteriores que no tenía interés en gobernar el reino de España habiendo mandado convocar una "asamblea general" de diputaciones de las provincias y de las ciudades para conocer cuáles eran sus deseos y sus necesidades. Los acontecimientos del 2 de mayo lo hacían conveniente para ganarse el apoyo popular. La Junta de Gobierno de Madrid fue la encargada de formar una comisión junto con miembros del Consejo de Castilla para la elaboración del texto de la convocatoria. Un texto redactado por el que fuera ministro de Gracia y Justicia, el marqués de Caballero, quién se cuidó mucho de cualquier tentación revolucionaria, manteniendo la presencia de las clases privilegiadas en la Asamblea de Bayona. A pesar de procurar esta apariencia de respeto por la decisión de los españoles, ya se conocía que el nuevo monarca sería su hermano José, pues había requerido ya con anterioridad, el 12 de mayo, al Consejo de Castilla que le pidieran la designación de este como monarca en un intento de obtener mayor legitimación. A pesar de la ambigüedad de la respuesta del Consejo, Napoleón la considera suficiente y el día 6 de

62. O'DONELL, H.: La campaña de Trafalgar..., op. cit., p. 275.

63. CAYUELA FERNÁNDEZ, J.: "Nelson y el bloqueo de Cádiz...", op. cit., p. 249. 
junio de 1808 José I fue proclamado "rey de España y de las Indias", antes de haber llegado a la península, y ni siquiera Bayona. Llegaría poco después, estando ya presente cuando la Asamblea de Bayona inició sus sesiones el día 15 de junio bajo la presidencia de Miguel José de Azanza, quien fue ministro y virrey, con la lectura de una circular que ordenaba al Consejo de Castilla hacer pública la proclamación del nuevo rey ${ }^{64}$. El 30 de junio tuvo lugar la última sesión con la presencia de 91 diputados, entre ellos José de Mazarredo y su amigo Mariano Luís de Urquijo, que será secretario general de la Asamblea. Ambos darán muestras de ser unos modernos ilustrados, al anteponer a su indiscutido apego por su tierra de origen la visión de una España dotada de un gobierno central fuerte capaz de emprender grandes reformas. No harán ningún esfuerzo por evitar la asimilación de los territorios forales vascos al resto de provincias cuando el nuevo texto constitucional extinga la obligación de hidalguía para ostentar cargo público, la extensión de un único código civil de leyes a todo el país, la traslación de las aduanas del interior a la costa, la facultad del gobierno para designar tribunales independientemente de que fueran o no naturales de allí, etc. Si bien se opusieron a que prosperase una clausula inicialmente incluida que derogaba expresamente los fueros, y se consensuará lo que será una constante en las constituciones hasta hoy. Una disposición que pospone la decisión de cómo se articulará el interés de las provincias vascongadas y del conjunto de España en un futuro, en este caso las primeras Cortes. De momento, era suficiente el conjunto de articulado que los dejaba en letra muerta ${ }^{65}$.

Todos ellos ilustrados, eran afrancesados que se mantienen dentro de la legalidad constitucional, pues hasta la fecha se ha producido un proceso de abdicaciones que había transmitido los derechos a una nueva dinastía de manera humillante sin resistencia de sus depositarios en contra del criterio de todos. Se mantiene el acatamiento a la Junta de Gobierno de Madrid quien ha convocado la Asamblea y el Consejo de Castilla respeta hasta la fecha todas las decisiones. Aunque éste último no llegará a jurar y hacer publicar la nueva Constitución porque sus miembros se enteraron a tiempo de la noticia de la victoria española de Bailén ${ }^{66}$ entre los días 18 y 20 de julio de 1808. Con anterioridad a ese acontecimiento España no está envuelta en una Guerra por la Independencia, sino en una contienda civil entre el bando del orden y la legalidad, y el del caos y la insurrección ${ }^{67}$. Las memo-

64. MORENO ALONSO, M.: José Bonaparte. Un rey republicano en el trono de España. Madrid. La Esfera de los Libros, 2008, pp. 208223.

65. SÁNCHEZ ARRESEIGOR, J.J.: Vascos contra Napoleón. Madrid. Actas, 2010, p. 120.

66. MORENO ALONSO, M.: José Bonaparte..., op. cit., p. 216.

67. CERVERA PERY, J.: "Mazarredo: un marino ministro de José Bonaparte", en VV.AA.: José de Mazarredo y Salazar. XXXIX Jornadas de Historia Marítima en Madrid (octubre 2009). Madrid. Instituto de Historia y Cultura Naval, 2010, p. 87. 
rias de Azanza y O’Farril recogen la justificación que les condujo a todos ellos a posicionarse junto con la nueva dinastía ${ }^{68}$.

La victoria de Bailén será un revulsivo que provocará que muchos de los que apoyaron al nuevo monarca, lo abandonen, como el jurista Ranz Romanillos, verdadero redactor de la propia Constitución de Bayona, que al margen de cualquier polémica historiográfica fue la primera en nacer, la primera en establecer la base de un pacto entre la Corona y el pueblo, y la primera en presentar al monarca como el primer rey constitucional de la historia de España. La nueva constitución, heredera de las constituciones francesas de la República, dotará al Estado de instituciones modernas, con dos cámaras de representación, el Senado y las Cortes, y sustituirá los antiguos Consejos del Antiguo Régimen en ministerios. La supremacía de la Ley queda sancionada al quedar todos los poderes supeditados a ésta, se establece un único código de leyes civiles y criminales que afectan a la totalidad del reino de España y las Indias, se abole la tortura, se crea un único sistema de contribución igual para todos, etc. En definitiva, suponía la introducción de una monarquía nueva de carácter republicano. Sin romper con el Antiguo Régimen totalmente, a diferencia de la de Cádiz que sí lo hará, se trata más de una constitución reformista que busca atraerse a los notables ilustrados ${ }^{69}$. Entre ellos figurará Mazarredo.

\section{Un gobierno de ilustrados reformistas. Los amigos de Mazarredo}

En la designación de su gobierno evitará igualmente José Bonaparte una ruptura radical con el Antiguo Régimen, confirmando inicialmente al que fuera primer secretario de Estado con Carlos IV, Pedro de Cevallos, a pesar de su relación de parentesco con Godoy. Aunque, considerado mediocre por Napoleón, abandonará pronto al nuevo rey pasándose a la causa patriótica. El nuevo rey también incorporará a algunos de los designados por Fernando VII en su breve gobierno como Azanza y O’Farrill, admirador declarado de Napoleón, como

68. "El estado de deferencia a que llegó a ponerse la Europa respecto al Imperio francés, y la situación en que veíamos a nuestra España, nos hicieron siempre inferir que la suerte de ésta esta ba limitada a uno de estos tres casos: o de ser gobernada por un Príncipe de la dinastía que rey naba en Francia; o ser dominada, y agregada a esta potencia; o ser desmembrada en pequeños Estados, por común acuerdo con los demás de Europa. Entre estos extremos no podía ser dudosa la preferencia del primero". Pero quando las transacciones de Bayona nos privaron de nuestro Rey; quando no pudo optarse sino entre la anarquía y una anarquía constitucional, entre los males de la conquista y un gobierno independiente; a vista de una guerra heroica, pero dilatada y sin probabilidad de un feliz término; es bien disculpable que el partido de la sumisión no fuese dudoso para muchos, y jamás será un delito para ninguno". AZANZA, M.J. y O'FARRILL, G.: Memoria de D. Miguel José de Azanza y D. Gonzalo O. Farrill, sobre los hechos que justifican su conducta política desde marzo de 1808 hasta abril de 1814. París. P.N. Rougeron, 1815, p. 199.

69. MORENO ALONSO, M.: José Bonaparte..., op. cit., pp. 222223. 
ministro de Guerra, y se atraerá a aquellos que sufrieron la marginación de Godoy, como Urquijo, el conde de Cabarrús y el propio Mazarredo. Sustituiría al inicialmente designado como ministro de Marina Francisco Gil de Lemos por indicaciones del propio Napoleón, entendemos que no tanto por una cuestión de afinidad pues ya hemos visto las diferencias entre ambos personajes, sino por su profesionalidad y prestigio entre los marinos. En definitiva, era "el mejor de los almirantes de España", según la esposa del hispanista contemporáneo Henry Richard Vassal Fox, Lady Holland. También intentará integrar en su gobierno a intelectuales como Jovellanos, quien recibe el nombramiento de Ministro del interior, pero que no acepta al considerar que la nación ha manifestado de manera clara y contundente su rechazo al nuevo rey por la forma engañosa en que se produjo y el escarnecimiento que padeció, apelando a la capacidad de los españoles de crear una nueva constitución sin necesidad de injerencias extranjeras. A Mazarredo, que era su amigo, le dirá que "la guerra civil era inevitable"70. O'Farrill y Mazarredo pensaron que una política conciliadora y de atracción podían convencer a muchos de aquellas figuras destacadas de la vida política, social y cultural a las que les unía una vieja amistad ${ }^{71}$. El nuevo monarca se posicionará en estos primeros momentos con esta política de apaciguamiento frente al resto de franceses que reclamaban una política de "O avance, o represión, o dispersión de los rebeldes" ${ }^{\prime 72}$.

Además de los hombres de su gobierno, José procuró la adhesión de la nobleza y Grandes de España, que poco a poco irán mostrando su desafección ausentándose de la Cortes con excusas. Un caso excepcional será la del duque de Frías, Diego Fernández de Velasco. Intelectuales como Moratín, o artistas como Goya también se adherirán al proyecto reformista de José I. Goya, quien era amigo personal de Mazarredo, encarnará a través de su obra en buena medida la paradoja que sustenta el apoyo al nuevo rey, al que muchas figuras se adhirieron por afinidad reformista e ilustrada, pero a los que repugnaba la crueldad de la guerra, posicionándose con su sufrimiento. En el caso de Mazarredo, tanto es así que llegará a insinuar al rey en alguna ocasión su salida del gobierno si se aplica una política de rigor contra la población ${ }^{73}$.

José I Ilegó a Madrid el 20 de julio de 1808, donde le recibieron algunos de sus ministros que ya habían Ilegado, como el propio Mazarredo, a quien poco después nombra capitán general de Marina. La acogida de la población fue inexistente como podía preverse después de la encarnizada represión que sucedió al 2 de mayo.

70. MORENO ALONSO, M.: Idem, op. cit., pp. 221260.

71. ARTOLA GALLEGO, M.: Los afrancesados..., op. cit., p. 112.

72. ARTOLA GALLEGO, M.: La España de Fernando VII..., op. cit., p. 248.

73. MORENO ALONSO, M.: José Bonaparte..., op. cit., pp. 230295. 
La noticia de la derrota de Bailén en los días finales de julio conduce al rey a abandonar la capital sin oponer resistencia, en contra del criterio militar de algunos como el propio Mazarredo quienes descorazonados ${ }^{74}$ proponen la defensa de Madrid con la creación de tres ejércitos. Acompañará en agosto al rey en el repliegue hasta situarse al norte del valle de Ebro, en Miranda de Ebro y después de establecerse la Corte en Vitoria. Entre agosto y octubre Mazarredo será enviado a Bilbao para sofocar la insurrección que se ha producido en Vizcaya, convocar Juntas Generales ${ }^{75}$, establecer milicias urbanas ${ }^{76}$ y someter a juramento de fidelidad a todos los funcionarios del estado ${ }^{77}$. De todos estos acontecimientos y actuaciones quedará testimonio en la abundante correspondencia remitida a José I acerca de su misión ${ }^{78}$. Reunida la Junta General del Señorío, convencerá a los asistentes para que aceptasen al nuevo rey como Señor de Vizcaya ${ }^{79}$. En aquellas juntas que presidió a finales de agosto quedan recogidos los puntos básicos del pensamiento afrancesado en el discurso pronunciado.

La conveniencia nacional, apelando a la razón frente a la excitación de ciertos sentimientos que solamente provocarán grandes males y reacciones ya inútiles $^{80}$. La unidad nacional frente posibilidad de que el emperador, para

74. ARTOLA GAlLEGO, M.: La España de Fernando VII..., op. cit., p. 253.

75. A.M.N. Colección "Antonio de Mazarredo". Leg. 2356. Bilbao, 1808, 19 de agosto. Decreto sobre la Junta General Extraordinaria que deberá celebrar el señorío de Vizcaya bajo la presidencia de Don José de Mazarredo, conforme a la instrucción que acompaña, folio 110.

76. A.M.N. Colección "Antonio de Mazarredo". Leg. 2356. Bilbao, 1808, 30 de agosto. Car ta de Mazarredo a José Bonaparte en la que le reporta que en cumplimiento de "su real instruc ción que procurase el establecimiento de milicias urbanas enteramente destinadas a mantener el orden y la propiedad y a reprimir todo movimiento sedicioso... acordaron (se refiere a las Juntas Generales) que en todos los pueblos haya una quadrilla armada de hombres buenos y honrados... los quales se ocupen a la orden de las Justicias..." folio 80.

77. A.M.N. Colección "Antonio de Mazarredo". Leg. 2356. Vitoria, 1808, 1 de octubre, decreto de Don José Bonaparte firmado por Gonzalo O'Farrill sobre el juramento de fidelidad que deben prestar todos los que reciben sueldo o pensión del Estado, folio 113.

78. A.M.N. Colección "Antonio de Mazarredo". Leg. 2356. Bilbao, 1808, entre 21 de agosto y el 30 de octubre. Cartas de Don José de Mazarredo a Don José Bonaparte desde su llegada a Bilbao hasta su llegada a Vitoria, sobre la insurrección de Vizcaya, la desolación causada por las tropas francesas, la detención de diversas personas, establecimiento de milicias urbanas, gobierno de la Iglesia, etc, relacionados con su cargo de Ministro de Justicia de Bonaparte, folios 70100.

79. SÁNCHEZ ARRESEIGOR, J. J.: Vascos..., op. cit., p. 76.

80. "Ni se os oculta, pueblos de Vizcaya, que estos males de aquí, y los incalculables que ha padecido y padece el reyno todo, vienen mucho del error en que se ha hecho caer a la opi nión pública excitándola a que prevalezcan ciertos sentimientos ya inútiles del corazón sobre la razón y la conveniencia". A.H.N. Estado, Leg. 3004 (Expediente 20), 1808, 29 de agosto, acta de las Juntas Generales Extraordinarias del Señorío de Vizcaya celebradas los días 26, 27 y 28 de agosto en Bilbao y presididas por José Domingo de Mazarredo, Ministro de Marina, página 8/20. 
garantizar la seguridad de Francia, secesione los territorios al norte del Ebro integrándolos en Francia ${ }^{81}$.

El adecuado abastecimiento de las tropas francesas mediante el nombramiento de una comisión designada por la administración territorial, en este caso "bajo las órdenes de la Diputación". Y por último el paquete de reformas encaminadas a incentivar la actividad y desarrollo económico mediante la "libertad de industria marítima", aranceles proteccionistas frente a productos extranjeros, la "extinción de la deuda nacional", y la promesa de acabar con el antiguo régimen fiscal que no respeta la privacidad de las casas y libros de cuentas ${ }^{82}$. De la bonhomía de Mazarredo y sentido de responsabilidad hacia Vizcaya dejará testimonios mientras forma parte del gobierno josefino cuando consiguió del rey reducir de ocho a cuatro millones de reales la contribución de Bilbao. Él mismo llegará a pagar las contribuciones de dos pueblos que no podían ${ }^{83}$.

A Vitoria llegará el emperador a comienzos de noviembre al frente de la "Grande Armée" a reunirse con su hermano, en un encuentro del que será testigo Mazarredo. En aquellos días Mazarredo, como el resto de ministros, volverá a mostrar su disconformidad y autonomía en la defensa de los intereses españoles frente al emperador al rechazar cualquier posibilidad estratégica de secesión de los territorios vascongados para su integración en Francia como se pretendía o de conformar un sistema político común entre Francia y España ${ }^{84}$.

Las tropas francesas devolverán el día 3 de diciembre a José I a Madrid. Comenzará un periodo de sometimiento militar del país que alejará progresiva y definitivamente cualquier posibilidad de un reinado estable que contase con el apoyo popular. El rechazo era generalizado hacia el "intruso", y como tal sería visto.

El ensañamiento popular contra los franceses y sus valedores, así como la cruenta respuesta y desmanes de las tropas franceses en su retirada después de abandonar Madrid habrán dejado un país en contra. Bilbao será un exponente

81. "Y si la desgracia hiciese que llevada la resistencia a una devastación, repugnase el corazón de nuestro soberano reinar sobre cenizas y escombros, los ejércitos franceses pasarían el Ebro y toda su izquierda, esto es, toda la Cataluña, casi todo Aragón, Navarra entera, Álava, Guipúzcoa, Vizcaya y la tierra comprendida más acá de la línea, desde el nacimiento del Ebro hasta Santoña sería parte integrante de la Francia". A.H.N. Estado, Leg. 3004 (Expediente 20), 1808, 29 de agosto, acta de las Juntas Generales Extraordinarias del Señorío de Vizcaya cele bradas los días 26, 27 y 28 de agosto en Bilbao y presididas por José Domingo de Mazarredo, Ministro de Marina, página 9/20.

82. A.H.N. Estado, Leg. 3004 (Expediente 20), 1808, 29 de agosto, acta de las Juntas Gene rales Extraordinarias del Señorío de Vizcaya celebradas los días 26, 27 y 28 de agosto en Bilbao y presididas por José Domingo de Mazarredo, Ministro de Marina, páginas 11 12/20.

83. BARBUDO DUARTE, E.: Don José de Mazarredo..., op. cit., p. 129.

84. ARTOLA GALLEGO, M.: Los afrancesados..., op. cit., p. 133. 
de la convulsión que ha provocado la llegada de los franceses, cambiando hasta seis veces de manos, tras sufrir una revolución, una gran batalla y dos saqueos, hasta que el 2 de noviembre 1808 se hicieron definitivamente con la ciudad. A pesar de ello, en las Provincias Vascongadas el rechazo imposibilitará prácticamente que vivan los franceses y los cargos públicos españoles de la nueva administración josefina, obligando a la familia del propio almirante Mazarredo a abandonar Bilbao para refugiarse en Francia ${ }^{85}$. Al contrario, su pariente Francisco de Mazarredo, dedicó su gran fortuna a la financiación de tres batallones para luchar contra los franceses, teniendo que huir a Málaga después de la victoria de José I donde continuó financiando un regimiento para la defensa de Cádiz ${ }^{86}$.

Una vez restablecido José I en el trono de Madrid, en el proceso de imponer el orden y reforzar la presencia nueva administración josefina en el reino, decidirá en febrero de 1809 el envío de siete comisarios regios a las diecisiete provincias que apenas controlaba. Mazarredo es enviado a Galicia de cuyo viaje deja testimonio en la reclamación de gastos que hace a la Hacienda ${ }^{87}$, aunque no pasará de Benavente ${ }^{88}$ por no haber sido consolidado el sometimiento de Galicia tras la victoria de la batalla de Elviña en enero de ese mismo año. En junio después de la batalla de Puentesampayo perderán definitivamente este territorio.

Comienzan los grandes días del reinado de José I en que emprende su programa reformista. Se suprimen aduanas interiores, se abolen derechos señoriales, se establece una nueva división territorial en treinta y ocho prefecturas ${ }^{89}$, se crean nuevas instituciones de beneficencia, culturales, educativas y comerciales. Se promovió la reactivación económica e iniciativas industriales introduciendo medidas relacionadas con la teoría liberal clásica. Un ejemplo de ello será la reactivación que vivirá la Sociedad Matritense de Amigos del País, de la que será nombrado Mazarredo vicedirector. Los ejércitos franceses alcanzarán éxitos consecutivos desde la victoria de Uclés en enero de 1809, momento en el que el emperador abandona España dejando a los mariscales Soult y Ney al frente del ejército francés, hasta obtener la derrota del ejército de la Junta Central en Ocaña en noviembre de 1809. La resistencia quedaba reducida a Andalucía, siendo finalmente sometida, a excepción de Cádiz ${ }^{90}$. La Junta se muestra indefensa ante la capitulación de Andalucía.

85. MORENO ALONSO, M.: José Bonaparte..., op. cit., p. 273.

86. SÁNCHEZ ARRESEIGOR, J. J.: Vascos..., op. cit., p. 65.

87. A.M.N. Colección "Antonio de Mazarredo". Leg. 2354, 1809, 8 de julio, cuenta de lo que adeuda la Hacienda a Don José de Mazarredo, correspondiente a sus haberes de los años de la fecha, folio 162 .

88. ARTOLA GALLEGO, M.: Los afrancesados..., op. cit., p. 261.

89. Uno de los secretarios de prefectura sería José Ignacio Altuna, sobrino de Mazarredo. LÓPEZ TABAR, J. 2011: Los famosos traidores..., op. cit., p. 61.

90. MORENO ALONSO, M.: José Bonaparte..., op. cit., p. 310. 
Pero hemos visto el carácter provisional de esos éxitos, haciendo que la situación no sea sostenible por mucho tiempo. En territorios como Valencia o como Galicia que a pesar de unas primeras victorias francesas, pronto se revierte la situación como hemos visto por la reacción popular de las guerrillas y patriótica de las Juntas apoyados por los ingleses. El drenaje de tropas hacia las campañas continentales y el desgaste que producía un país levantado en armas contra los franceses pronto hicieron la situación insostenible. A finales de 1810 el abastecimiento era insuficiente y faltaban los recursos. La presencia de la administración josefina y su capacidad de recaudación fiscal se reducía y complicaba cada vez más en un país del que perdían día tras día el control especialmente en las provincias periféricas, de la costa. El propio Mazarredo se dirigirá en los primeros meses de 1811 al rey para solicitar raciones militares con las que alimentar a su familia. El rey se ausentará entre abril y julio de 1811 para acudir al encuentro con su hermano en París y tratar de obtener recursos para evitar el desastre. Su situación económica es desesperada y por eso decide viajar a París, ante la falta de respuesta a sus peticiones por carta, con la excusa del nacimiento del hijo del emperador. No obtendrá ninguna concesión, y a su regreso en julio, reunido el consejo de ministros en el que participará Mazarredo la única preocupación será mantener el control de las provincias del centro y garantizar la recolección de la cosecha para el sostenimiento de la corte y las tropas. Todo resultará inútil como consecuencia de la apropiación de la guerriIla de las cosechas, y del incentivo con elevadas primas que pagan los ingleses a los campesinos ${ }^{91}$.

Ante los constantes clamores de su hermano por la miseria que sufre por el desabastecimiento y la desesperación por la sucesión de derrotas que se acumulan, Napoleón no sabe qué medios ni fuerzas emplear, ni los resultados a conseguir. Se siente hastiado por los problemas de España, y el 14 de enero con la excusa de la derrota de Tarragona ordena la integración de los territorios catalanes en Francia, sin consultarlo previamente con su hermano en España. El estupor y desaliento entre los afrancesados es total ${ }^{92}$. El fin del reinado de José I se acerca. A partir del verano de 1812 a la guerra de guerrillas que se está librando con considerable desgaste, habrá de enfrentarse a la ofensiva los aliados anglo-hispano-portugueses. La derrota del ejército francés en la batalla de Arapiles el 22 de julio obligará por segunda vez a la huida de Madrid del rey Bonaparte hacia el norte. Mazarredo que murió en Madrid a los sesenta y siete años el 29 de julio de 1812 de un fuerte ataque de gota ${ }^{93}$, evitó vivir pocos días después la penosa salida del rey en las terribles semanas de finales de julio y agosto de 1812. La Gazeta de Madrid del 6 de agosto de 1812 recoge la necro-

91. ARTOLA GALLEGO, M.: Los afrancesados, pp. 189209.

92. ARTOLA GALLEGO, M.: Idem, pp. 208209.

93. BARBUDO DUARTE, E.: Don José de Mazarredo..., op. cit., p. 130. 
lógica de su fallecimiento ${ }^{94}$. El Ministerio de la Marina quedó integrado al de Guerra. Su viuda, María Antonio de Moyua, es compensada con una pensión como acredita la correspondencia con el Ministerio de Hacienda ${ }^{95}$.

Las tropas francesas conseguirán frenar a Wellington en Burgos y regresará José I a Madrid, aunque por poco tiempo. Durante 1813 las tropas francesas irán perdiendo tropas, abandonando plazas y replegándose hasta que en la batalla de Vitoria el día 21 de junio de 1813 concluyera con la expulsión definitiva, cruzando los Pirineos los aliados hacia París en octubre de 1813.

\section{Los hombres de la marina. Aislamiento de Mazarredo}

Los militares afrancesados tuvieron poco peso en la guerra de la Independencia $^{96}$. El papel que pudo jugar Mazarredo fue escaso en una Marina prácticamente inexistente durante un conflicto en el que casi todas las operaciones fueron terrestres. Como ya ocurriera cuando ejerció el mando de la escuadra del Océano en Brest, todas sus acciones se verán encaminadas a la salvaguarda de la Marina frente a injerencias externas, y sobre todo, frente a mandatos franceses que comprometieran su propia supervivencia obviando la incapacidad operativa por falta de recursos humanos y materiales. Aunque pocos fueron los marinos, como los militares en general, que se adscribieron a la nueva dinastía francesa, Mazarredo para esta tarea al menos contará con dos almirantes: José Justo Salcedo y Pedro de Obregón ${ }^{97}$.

El primero había sido escogido para sustituir a Cayetano Valdés al mando de la escuadra de Cartagena por la negativa de aquel de conducir los navíos españoles a reunirse en Tolón con los franceses en febrero de 1808 y llevarlos al puerto de Mahón, probablemente consciente de la situación de invasión que se percibía que se estaba viviendo. Ello provocó el enojo de Murat y el requerimiento a Godoy para que procediese con la sustitución de Valdés, haciéndolo por Salcedo, quien a su vez rehusó hacerlo al coincidir su toma de mando con los hechos de mayo, quedando los barcos en Mahón. Es bastante significativa esta desobediencia respecto del escaso grado de autoridad que tenían los mandos centrales, el relajamiento en la disciplina, y sobre todo la confusión que se vivía en aquellos momentos. Sorprendentemente, a pesar de ser partidario de la alianza con Francia, desobedeció no asumiendo el mando e incluso participan-

94. Gazeta de Madrid, 6 de agosto de 1812.

95. A.M.N. Colección "Antonio de Mazarredo". Leg. 2355, 1812, 8 de agosto, representa ción sobre la situación económica de Don José de Mazarredo a su muerte y cartas sobre la con cesión de pensión a su viuda, folios 4761 .

96. GARCÍA CARCEL, R.: El sueño de la nación indomable. Los mitos de la Guerra de la Independencia. Madrid. Temas de hoy, 2007, p. 187.

97. CERVERA PERY, J.: "Mazarredo: un marino ministro...", op. cit., pp. 9293. 
do en la defensa posterior contra los franceses, hasta que más adelante en 1809 en un giro radical se pasó al bando afrancesado ${ }^{98}$ y se puso a las órdenes de Mazarredo, siendo comandante general en la bahía de Cádiz de la Marina afrancesada. La precipitación de los acontecimientos y la confusión que generan lo explican y nos sirve para retratar la posición de algunos de los marinos más destacados en aquel episodio histórico.

El 20 de marzo Godoy había sido exonerado de su título de almirante, y el Almirantazgo, que apenas había durado un año, fue sustituido por el Consejo Supremo de Marina, al mismo nivel que el de Guerra, presidido por el rey, Calos IV. En ese contexto se encontraba la marina cuando se produce el cambio dinástico en Bayona y la designación por José I de Mazarredo al frente del nuevo Ministerio de la Marina pocos meses después, en julio de 1808.

Además de Mazarredo, otro destacado marino, Miguel Ricardo de Álava ${ }^{99}$, estuvo presente en Bayona. Aunque no tuvo ningún protagonismo ni participó en las deliberaciones por no considerarse así mismo preparado para opinar en cuestiones políticas. Allí se encontraba porque se lo mandaron desde la Junta Central en representación de la Marina ${ }^{100}$. Pronto abandona la lealtad a la nueva dinastía francesa cuando es testigo directo de la coacción a punta de bayoneta a los junteros alaveses para que acepten al nuevo rey francés. Más adelante cuando Mazarredo, Salcedo y Obregón intenten atraerse a la causa bonapartista a su tío Ignacio María de Álava, comandante general de la escuadra de Cádiz, éste les responderá en duros términos de reproche por su posicionamiento junto al rey Bonaparte ${ }^{101}$.

Comenzada la guerra de la Independencia y conseguida la victoria de Bailén frente a los franceses provocando su huida hacia el norte, la Junta Central Suprema restablece las Secretarías de Estado y la Universal de Marina, designando a su propio ministro de marina el 16 de octubre 1808. La fatalidad propia de una guerra fratricida querrá que sea Antonio de Escaño, quien sea designado como contrario de Mazarredo en el lado patriótico. Escaño había sido para Mazarredo "el más adicto de sus subordinados y el más entrañable de sus colaboradores $^{\prime \prime 102}$, pero se había negado a prestar juramento de fidelidad y obediencia a José Bonaparte provocando su nuevo nombramiento que se encontrase enfrentado a su viejo amigo y compañero. Estará al frente de la Marina patriótica hasta el 29 de enero de 1810 en que será designado como uno de los cinco miembros

98. Ibidem.

99. Sobrino de Ignacio María de Álava, uno de los más estrechos colaboradores, y de los más queridos amigos, de Mazarredo.

100. SÁNCHEZ ARRESEIGOR, J. J.: Vascos..., op. cit., p. 120.

101. CERVERA PERY, J.: "Mazarredo: un marino ministro...", op. cit. p. 94

102. BARBUDO DUARTE, E.: Don José de Mazarredo..., op. cit., p. 128. 
integrantes del Consejo de Regencia nacida para sustituir a la Junta Central Suprema. Le sustituirá Gabriel Ciscar al frente del Despacho de Marina, quien a su vez acabaría después formando parte de la segunda regencia, siendo sustituido el 23 de junio de 1812 en la Secretaría del Despacho de Marina por José Vázquez de Figueroa.

El segundo hombre que seguirá a Mazarredo en la nueva administración josefina, Pedro Obregón, se encontraba en el momento de la invasión francesa al frente de la comandancia general de Ferrol. Aunque aceptará el nuevo cambio de dinastía, de acuerdo con Mazarredo dilatará reiteradamente cumplimentar las órdenes francesas de reunir la escuadra que allí se encontraba con la francesa en Brest. No saldrían de El Ferrol ${ }^{103}$.

Ambos marinos gozarían de la confianza de Mazarredo, pero no protagonizarían ninguna operación al carecer como había sido una constante de suministros materiales y tripulaciones para dotarlas, y ahora tampoco oficiales a los que encargar el mando, pues la mayoría se habían pasado al lado patriótico y estaban luchando en operaciones terrestres ${ }^{104}$. Poco después de comenzada la guerra ni siquiera tendrán navíos, pues veremos cómo acabarán perdiendo los que se encontraban en El Ferrol a manos del lado patriótico. La Marina josefina existió solo de nombre, y a la muerte de Mazarredo se integraría en la cartera de Guerra dirigida por O`Farrill como vimos. La plantilla del ministerio fue tan solo de 17 personas, incluido él mismo y el portero ${ }^{105}$.

A pesar de la amargura y decepción que probablemente hubo de sufrir Mazarredo al ver como sus antiguos amigos y compañeros se convertían en sus enemigos ahora, "siempre se halló dispuesto a proteger cuantos compañeros de la Armada eran perseguidos por sus ideas contrarias al régimen"106 de José I.

\section{Fractura de la flota e inacción}

Si ya hemos visto la confusión y carencia de mando en los meses previos a los acontecimientos de mayo, a partir del levantamiento se intensificará la falta de control de los medios y hombres del ejército, y de la Armada en ambos bandos. Las cifras respecto del número de unidades con las que contaba la Marina después de Trafalgar, varía notablemente según autores desde los 16 a los 64 navíos, de las 45 a las 21 fragatas, y de los 141 a los 156 buques menores, entre corbetas, jabeques, urcas, bergantines, paquebotes, goletas, etc. ${ }^{107}$

103. CERVERA PERY, J.: "Mazarredo: un marino ministro...", op. cit., pp. 9293.

104. Ibidem.

105. LÓPEZ TABAR, J.: Los famosos traidores..., op. cit., pp. 7175.

106. BARBUDO DUARTE, E.: Don José de Mazarredo..., op. cit., p. 129.

107. "Según Fernández Duro se contaban con 42 navíos, 30 fragatas, nueve corbetas, cua tro jabeques, 15 urcas, 50 bergantines, cuatro paquebotes, 38 goletas, 10 balandras y 15 uni 
Independientemente de su número, la Armada española desarrolló una escasa y discontinua actividad durante la guerra de independencia en ambos bandos, como ha venido sosteniendo la historiografía tradicionalmente. Aunque más o menos acertadamente, ya que hay que introducir matices sobre todo en lo referido al bando patriótico ${ }^{108}$, que tendrá aún protagonismo pues acabará haciéndose con los navíos y mayoría de barcos. La iniciativa también partirá de este bando en la acción llevada a cabo por la escuadra formada por cinco buques españoles al mando de Juan Ruiz de Apodaca en la bahía de Cádiz contra la flota francesa. El almirante Rosilly, quien había sustituido a Villeneuve, se encontraba al mando de la escuadra francesa fondeada en la bahía de Cádiz, cuando en junio llegaron las noticias de la Junta de Sevilla del levantamiento español contra las tropas napoleónicas. Se saldó con una victoria del bando patriótico el 14 de junio de 1808. Los buques apresados a los franceses en la bahía de Cádiz, así como poco después en Vigo, y añadidos a los españoles fondeados en Cádiz en el momento de la guerra de la Independencia cumplirían aún algunas misiones al servicio de las autoridades refugiadas en Cádiz ${ }^{109}$ tras el retorno de José I a Madrid en noviembre de 1808. Pronto se incrementaría el número de barcos, gracias a Mazarredo de manera involuntaria.

En el lado josefino la capitulación de Ferrol en enero de 1809 dejará en sus manos el arsenal más importante y un total de 16 buques. Mazarredo pondrá a su frente a Pedro de Obregón y dilatará de manera continuada cualquier salida de puerto de los buques para reunirse con la flota francesa en Brest ${ }^{110}$. Esta acción personal de Mazarredo posibilitará que estos buques sean recuperados por la Junta Central y trasladados a Cádiz cuando tomen el Ferrol en mayo de

dades de fuerza sutiles, mientras Cervera Pery ofrece los siguientes datos: 42 navíos, 21 fragatas y 32 corbetas, y Rey Joli no hace pasar de los 16 navíos, en tanto que el almirante Indalecio Núñez Iglesias y José María Blanco Núñez, sobre su cómputo de buques en 1793 y descontan do las pérdidas de Trafalgar y dado que el Argonauta fue el último navío construido en España antes de 1808, la cifra que sugieren es la de 64 navíos, 45 fragatas y 156 buques menores. En BORDEJÉ Y MORENCOS, F.: Crónica de la marina española en el siglo XIX, 1800-1868 (Tomo I). Madrid. Ministerio de Defensa, 1999, p. 49.

108. RUIZ GARCÍA, V.: Las naves de las Cortes..., op. cit., p. 11.

109. RUIZ GARCÍA, V.: Idem, pp. 5657.

110. "El emperador Napoleón envió con un contralmirante personal de su marina para tri pular once buques de guerra de gran porte, y cuatro menos y muchos pequeños fondeados en Ferrol, pero Mazarredo llegó a tiempo para evitar tal despojo... El afán de servicio a su patria constituía en él una obsesión y para conseguirlo no reparaba en fatigas ni sacrificios. Supo que el emperador Napoleón tenía decidido incautarse de la escuadra española puesta en Ferrol y corrió veloz a Galicia para impedirlo... Escribió Mazarredo al gobierno de José Bonaparte dan do cuenta de este suceso y de sus trabajos de reorganización de aquellos buques, de los bata llones de marina y de la gente del arsenal, maestranza y presidio." A.M.N., Colección "Antonio de Mazarredo". Leg. 2353, 1913, junio, biografía de Don José de Mazarredo y Gortázar por Don Antonio de Mazarredo y Allende Salazar, folios 122123. 
$1809^{111}$, estando además perfectamente aprovisionados para hacerse a la mar en septiembre $^{112}$. La escuadra de Cartagena no contaba, al haber sido desmantelada después de que Valdés hubiese preferido conducirla a Mahón en vez de a Tolón ya en 1808, a salvo de las tropas napoleónicas que habían invadido la península y bajo la protección de la marina británica. La España insular quedó excluida del dominio francés.

Estando del lado de la marina patriótica la balanza, ésta desarrolló su actividad enmarcada en tres misiones esenciales. La escolta de los convoyes de ultramar ${ }^{113}$, la defensa de Cádiz y el apoyo a la marina británica en operaciones combinadas, si bien el protagonismo no sería tan relevante como se ha pretendido por algunos historiadores navales, recayendo éste en la flota británica con quienes la Junta Central refugiada en Cádiz firmaría la paz el 14 de enero de 1809 después de enviar una comisión a Londres, entre los que estaba el propio Ruiz de Apodaca.

El dominio del mar por parte de los británicos y la disponibilidad de navíos y otro tipo de barcos en el lado patriótico posibilitará el cumplimiento de la primera de las misiones mencionadas. La escolta y transporte a bordo de caudales desde América. La Armada también participará en el traslado de tropas ${ }^{114}$ y personalidades, y a partir de 1810 los buques enviados para el transporte a bordo de los caudales de América apoyarán en la represión de la rebelión en las colonias. Aunque en menor medida que en épocas precedentes, será Cádiz quien mantenga el tráfico con América, habiendo el gobierno josefino asumido como "irremediable la pérdida del control de las colonias americanas. Pese a ello se mantuvo una mínima estructura burocrática a título nominal que funcionó hasta el final del reinado" a cuyo frente estuco como ministro de Indias Miguel José de Azanza ${ }^{115}$.

A Ignacio de Álava le encomendará la Junta Central, y la Regencia después, la defensa marítima de la bahía de Cádiz con una escuadra, posibilitando la entrada de las embarcaciones con tropas, barcos comerciales y personalidades procedentes de América y otros puntos peninsulares frente al acoso de la marina josefina. Álava tendrá enfrente a José Justo Salcedo. Como hemos visto, una vez hubo abrazado definitivamente la causa bonapartista tras la segunda entrada de José I en Madrid se desplazó a Cádiz en 1810 designado como su comandante

111. RUIZ GARCÍA, V.: Las naves de las Cortes..., op. cit., p. 53.

112. CERVERA PERY, J.: Marina y política en la España del siglo XIX. Madrid. Editorial San Martín, 1976, p. 43.

113. Para ampliar información acerca del transporte a bordo de los buques de caudales americanos véase el capítulo tercero de RUIZ GARCíA, V.: Idem, pp. 5982.

114. Para ampliar información sobre el transporte de tropas véase el capítulo tercero de RUIZ GARCÍA, V.: Las naves de las Cortes..., op. cit., pp. 119166.

115. LÓPEZ TABAR, J.: Los famosos traidores..., op. cit., p. 75. 
general. Actuando como "práctico en el acercamiento de los franceses a la Isla de León y establecimiento de sus posiciones. Ordenó la construcción y armamento de lanchas cañoneras y obuseras y faluchos, requisando tartanas y charangueros para el transporte de las tropas francesas" ${ }^{\prime 116}$ conformando éste el origen de la fuerza naval sutil bonapartista. En el lado defensivo de la Isla de León igualmente las fuerzas sutiles formaron parte esencial en el engranaje defensivo que permitió soportar el sitio ${ }^{117}$. La marina del lado josefino carecía de cualquier operatividad, y cuando se consiguió dotar algunos de los barcos, ocurrió que el oficial al mando pasó al otro bando, como el falucho Nuestra Señora del Carmen a las órdenes de alférez de navío Gabriel de Olivar ${ }^{118}$.

En el norte, excluida la marina josefina de cualquier posibilidad de participar en combates navales o tareas de mayor alcance y excluida del control del tráfico con América, se concentrará en la defensa y control de su costa frente al acoso británico. En abril de 1809 los británicos decidieron el bloqueo de todos los territorios peninsulares ocupados. La guerra naval en el norte será intensa, aunque a pequeña escala y protagonizada por fragatas y pequeñas embarcaciones que se dedicaban al acoso de la costa atacando las poblaciones con puerto. Si bien los barcos británicos estaban compuestos de dotaciones españolas de soldados para las tareas de asalto y desembarco, y éstas raras veces atacaban a la población limitándose a objetivos militares como la destrucción de las baterías costeras, ocurrirá que una enemistad secular con los ingleses dejará en estas localidades un pasado imposible de borrar. Así serán muchas las poblaciones que se destaquen por su defensa y captura de barcos y tropas británicas y españolas patrióticas durante el verano de 1809. La necesidad de vigilar la extensa fachada atlántica y la limitación de las tropas imperiales para semejante tarea a la vez que se domina todo el territorio conducirá a que en ese mismo año se intente organizar un servicio de centinelas costeros civiles debidamente equipados con un catalejo. Asimismo, en octubre de 1809 Mazarredo emitió un decreto para que todos los barcos españoles navegasen formando convoyes de al menos cuatro embarcaciones armadas con un cañón. La intensidad de los ataques anfibios crecía contra objetivos militares y el asalto y captura de los barcos españoles. En buena medida con la colaboración de los barcos de cabotaje

116. MARTÍNEZ VALVERDE, C.: La Marina en la Guerra de la Independencia..., op. cit., p. 66.

117. "Puede acordarse de que con la denominación de fuerzas sutiles se conoce a un con junto de pequeñas embarcaciones armadas generalmente con un cañón, o con uno o dos obu ses, o con un mortero, y empleadas tácticamente con estrategias propias de la guerrilla contra objetivos siempre próximos a la costa", en QUINTERO GONZÁLEZ, J.: "El bloqueo de la Isla de León" en VV.AA.: La Marina en la Guerra de la Independencia II y III. XXXVI y XXXVIII Jornadas de Historia Marítima en Madrid (abril 2008 y marzo 2009). Madrid. Instituto de Historia y Cultura Naval, 2010, p. 105.

118. CERVERA PERY, J.: "Mazarredo: un marino ministro...", op. cit., p. 94. 
de las poblaciones costeras que abastecían los navíos ingleses y después denunciaban el hecho como un asalto para reclamar indemnizaciones. Pero, el problema no era solo de pérdidas militares o de abastecimientos, sino también de población que de manera voluntaria se embarcaba en los navíos ingleses para su traslado y alistamiento con las tropas patrióticas establecidas en Galicia ${ }^{119}$.

La acción más destacada de los hombres de la marina josefina por la historiografía naval de este periodo está lejos de los escenarios de combate, y se refiere a la comisión en febrero de 1810 por parte del gobierno francés para que desde el Puerto de Santamaría conminasen a su rendición a la Junta de Gobierno de Cádiz y la Isla de León una vez ha finalizado la rendición de Andalucía. Sirviendo la constante referencia a este hecho para realzar la respuesta de lealtad a Fernando VII ${ }^{120}$ de las autoridades refugiadas en Cádiz. La realidad es que la marina josefina apenas tuvo una existencia y alcance más allá del nominal.

\section{Mazarredo y los afrancesados ante los desastres de la guerra}

Mazarredo pronto se mostrará preocupado por los hechos acaecidos como consecuencia de la guerra comenzada con el cambio dinástico, y será precisamente en su tierra de origen, el Señorío de Vizcaya, donde lo ponga pronto de manifiesto. Allí será enviado para sofocar la primera insurrección contra Bonaparte en agosto de 1808. Nada más Ilegar será receptivo con las numerosas solicitudes de ayuda y socorro con todas aquellas personas que han sido perjudicas cayendo en la indigencia como consecuencia de la insurrección de Vizcaya en agosto de 1808 y su represión por las tropas francesas. Prueba de ello es que desde la primera carta ${ }^{121}$ que dirige a José I relatando la situación en el Señorío ocupará esta preocupación siempre las primeras líneas ${ }^{122}$.

119. SÁNCHEZ ARRESEIGOR, J. J.: Vascos..., op. cit., pp. 310313.

120. CERVERA PERY, J.: "Mazarredo: un marino ministro...", op. cit., p. 94.

121. A.M.N. Colección "Antonio de Mazarredo". Leg. 2356, 1808, entre el 21 de agosto y el 30 de octubre de 1808, cartas de Don José de Mazarredo a José Bonaparte desde su llegada a Bilbao hasta su regreso a Vitoria, sobre la insurrección de Vizcaya, la desolación causada por las tropas francesas, la detención de diversas personas, establecimiento de milicias urbanas, gobierno de la Iglesia, etc.

122. "Conforme a las órdenes de V.M. he llegado esta mañana a esta villa de Bilbao y al momento envié al General Merlin la carta que V.N. me encomendó. No tengo por oportuno hablar a V.M. en esta primera carta de la desolación en que he hallado este país, y lo que haré en la primera siguiente específicamente y entretanto... confío en el benigno corazón de V.M. que la aplicación será como lo tenemos rogado los ministros en socorro de la indigencia de tan to infeliz para cuyo conocimiento he pasado oficio al gobierno municipal a fin de que me pase nómina de los más indigentes arruinados en esta villa y en las Anteiglesias cercanas de Albia, Deusto y Begoña.". A.M.N. Colección "Antonio de Mazarredo". Leg. 2356. Bilbao, 1808, 21 de agosto, carta de Mazarredo al rey José I, folio 70. 
La denuncia constante se mantiene en todas las cartas prácticamente. Va más allá de una cuestión de denuncia formal, consiguiendo que más adelante sean auxiliados y reparados económicamente por la hacienda real ${ }^{123}$.

Las actas de las Juntas Generales Extraordinarias convocadas días después recogen un discurso atribuido a él como presidente, donde se vuelven a poner de manifiesto los estragos provocados por la insurrección contra los franceses, y la respuesta de éstos. Se recoge una exhortación a la razón para poner freno a esa situación, que será una constante en los afrancesados ${ }^{124}$.

Finalizada su misión en Bilbao se incorporará a la corte establecida en Vitoria donde las tropas imperiales han acudido en auxilio de José I para avanzar sobre Madrid y recuperarlo después del primer repliegue. Probablemente uno de los acontecimientos que están más acreditados respecto de su preocupación por la población es el ocurrido allí, en la reunión de Napoleón con su hermano a comienzos de noviembre de 1808. El repliegue había sido realizado con grandes desmanes por parte de las tropas franceses infringiendo graves daños a la población, quienes a su vez reaccionaron proporcionalmente en su crueldad en una espiral fatal de violencia. El desprecio con el que Napoleón se refiere a la ingratitud del pueblo español al que solo ha tratado de traer el progreso, la paz y la modernidad, y hacia su clero especialmente del que responsabiliza de agitar al pueblo, inquieta a algunos de sus ministros, incluido el propio Mazarre$\mathrm{do}^{125}$. Le preocupaba la actitud que tendrían las tropas frente a la población, no tanto la alusión al clero, por el que mostrará como ilustrado desinterés cuando en alguna ocasión se dirija a él el cabildo de Bilbao trasladándole preocupación por la carencia de los mismos en las parroquias ${ }^{126}$. Relatará O`Farrill que Mazarredo llegará a replicar de nuevo a Napoleón, acerca de la preocupación por la reacción de las colonias americanas, que ello dependerá de la forma en que se comporten los generales franceses ${ }^{127}$.

123. A.M.N. Colección "Antonio de Mazarredo". Leg. 2356, 1808, 16 de septiembre, infor me remitido a José de Mazarredo por las autoridades locales de Bilbao informando de las asig naciones realizadas con el listado de personas con nombre y cantidades, folios 144154.

124. “... que prevalezcan ciertos sentimientos ya inútiles del corazón sobre la razón y la conveniencia en grado de que se tengan por nada los gemidos de la viuda, los llantos del niño hambriento, la miseria de las familias saqueadas o errantes y la desolación general. ¡Qué dolor que este escarceo de ideas se haya querido figurar un deber de conciencia, convirtiendo una misión únicamente de paz en fraguas de fuego que mares de sangre no basten a apagar". A.H.N. Estado, Leg. 3004 (Expediente 20), 1808, 29 de agosto, acta de las Juntas Generales Extraordinarias del Señorío de Vizcaya celebradas los días 26, 27 y 28 de agosto en Bilbao y presididas por José Domingo de Mazarredo, Ministro de Marina, páginas 8 9/20

125. MORENO ALONSO, M.: José Bonaparte..., op. cit., p. 300.

126. SÁNCHEZ ARRESEIGOR, J. J.: VasCOs..., op. cit., p. 148.

127. SÁNCHEZ ARRESEIGOR, J. J.: Idem, p. 88. 
Cuando las tropas francesas se encuentran ya agrupadas en noviembre y preparadas para la ofensiva que llevará de nuevo a José Bonaparte al trono en Madrid, los ministros que rodean al rey en Vitoria en un último intento de evitar un enfrentamiento fratricida firman y envían una carta a Madrid dirigida al presidente de la Junta Central Suprema, el conde Floridablanca, en la que en un último intento desesperado pedirán que envíen una diputación para negociar una paz, haciendo una declaración de los motivos que les habían conducido al apoyo del rey francés. Destacaban además del amor y respeto profesado a su persona, y del sentido del deber al que estaban obligados, por entender que de esta forma se evitaban las desgracias y desastres de una guerra ${ }^{128}$.

Cuando José Bonaparte es restablecido en el trono en Madrid y Mazarredo es enviado a Galicia en febrero de 1809 como comisario regio, en el cometido de su misión no dejarán de sucederse las quejas por los violentos procedimientos que utilizan contra la población los generales franceses, a los que responsabilizará de los males ocurridos a lo largo de los diferentes territorios del reino ${ }^{129}$. "Durante toda su época ministerial se halló siempre dispuesto para denunciar infatigablemente cuantos abusos y tropelías cometían los franceses"130. La predicción que le hiciera su buen amigo Jovellanos cuando le ofrecieron incorporarse a Bayona en 1808 se había cumplido. "La guerra civil era inevitable"131.

Sabemos por su correspondencia de los últimos años de vida de la agitación interior y dolor que le embarga por todos los acontecimientos ocurridos. Convaleciente por un ataque de gota se ausentará unos días de las reuniones, pero se dirigirá en esos días por carta emperador solicitando el perdón y autorizando el regreso a sus casas a aquellos que asustados abandonaron a José Bonaparte en su primera huida de Madrid ${ }^{132}$. Podemos adivinar como flaquea su adhesión a la causa bonapartista, y la desilusión que sufre ${ }^{133}$. El escenario que pensó podía evitarse con la aceptación del cambio dinástico había acabado produciendo enorme sufrimiento y destrucción a su país.

\section{Conclusiones}

El "colaboracionismo" josefino tiene un alcance diferente del que probablemente tenemos en nuestro imaginario como consecuencia de la Segunda Gue-

128. ARTOLA GALLEGO, M.: Los afrancesados..., op. cit., p. 118.

129. ARTOLA GALLEGO, M.: Idem, p. 148.

130. BARBUDO DUARTE, E.: Don José de Mazarredo..., op. cit., p. 129.

131. MORENO ALONSO, M.: José Bonaparte..., op. cit., p. 260.

132. A.M.N. Colección "Antonio de Mazarredo". Leg. 2356. Vitoria, 1808, 11 de noviem bre, minuta de Don José de Mazarredo al emperador excusándose de presentarse por su estado de salud y recomienda la indulgencia para los emigrados, folio 120.

133. CERVERA PERY, J.: "Mazarredo: un marino ministro...", op. cit., p. 94. 
rra Mundial, quedando enmarcado en un inicial proceso de tránsito legítimo de una dinastía a otro, del aparato político e intelectual del Antiguo Régimen al moderno del que todos participan, si bien en poco tiempo se descolgarán un buen número de personajes. Las motivaciones que conducen a Mazarredo a permanecer están igualmente revestidas de un "patriotismo incuestionable" del que dio muestras a lo largo de toda su carrera frente al gobierno francés, y del que daría nuevas muestras encontrando en la defensa del propio José I un medio para evitar el "intervencionismo, la arbitrariedad y el sojuzgamiento que ejercía Napoleón sobre España"134. En ese sentido es revisada su imagen desde un punto de vista historiográfico-militar, sin dejar de añadir como en el resto de casos de los afrancesados el sentido humanístico y cosmopolita propio de la ilustración. Tampoco hemos de dejar al margen otras consideraciones más personales como hemos visto. La forma en que la anterior dinastía de los Borbones y su gobierno trataron a su persona en los años anteriores, la manera en que fue sometido al ostracismo y persecución le condujeron probablemente al rechazo de aquellos, y a acoger con esperanza e ilusión el cambio. Al fin y al cabo, se trataba de una nueva forma moderna de patriotismo que no se centraba en la lealtad a un rey sino a un reino, independientemente de la dinastía que lo reinase. El inconveniente fue que los afrancesados tuvieron una percepción reformista e ilustrada que no consideró la reacción popular ${ }^{135}$.

De hecho, hasta su participación en la Asamblea de Bayona no había tenido pasado político, sino solo el prestigio de ser un buen marino. Acabará siendo ministro de una Marina "apócrifa" sufriendo el temprano desencanto de su cargo probablemente, y el rechazo de casi todos sus compañeros que hasta la fecha le habían demostrado el máximo respeto y admiración, incluso durante su periodo de ostracismo ${ }^{136}$.

Sin embargo, después de su muerte pronto es rehabilitada su figura. A instancias de su propia viuda, Doña María Antonia Moyúa, se inicia un expediente acerca de la conducta de Mazarredo con el ánimo de justificar su actuación y rehabilitar su figura' ${ }^{137}$. Avanzado el siglo XIX la Marina rehabilita su figura e incluso una corbeta recibe su nombre en $1847^{138}$. Pero, ni siquiera habrá que

134. CERVERA PERY, J.: Idem, p. 86.

135. SÁNCHEZ ARRESEIGOR, J. J.: Vascos..., op. cit., p. 460.

136. CERVERA PERY, J.: "Mazarredo: un marino ministro...", op. cit., p. 88.

137. A.M.N. Colección "Antonio de Mazarredo". Leg. 2354, 1818, 30 de septiembre, infor mación practicada a instancias de la viuda del General Mazarredo, Doña María Antonia Moyúa, para justificar su conducta en tiempo del Gobierno intruso, folios 191201.

138. A.M.N. Colección "Antonio de Mazarredo". Leg. 2355, 1847, 25 de mayo, comunica ción al Ministro de Marina, Don Juan de Dios Sotelo al teniente general Manuel Mazarredo, ministro de la Guerra, de la designación de una corbeta con el nombre del Teniente General José de Mazarredo por deseo de la reina Isabel II, folios 6263 . 
esperar a la rehabilitación posterior de su figura para encontrar palabras de admiración entre aquellos que lucharon en su contra, en el lado patriótico. El propio General Espoz y Mina tendrá ocasión de trasmitirle en una vista en Londres al exiliado José I en 1834 la veneración que sentía por algunos de sus ministros, Mazarredo entre ellos ${ }^{139}$.

139. MORENO ALONSO, M.: José Bonaparte..., op. cit., p. 435. 